\title{
The route to recall a dream: Theoretical considerations and methodological implications
}

\author{
Georgina Nemeth \\ Cognitive Neuroscience Research Unit, CFIN, Aarhus University, Denmark \\ gina.nemeth@gmail.com
}

\begin{abstract}
The goal of this paper is to shed new light on the relation between dream recall and dream experiences by providing a thorough analysis of the process that leads to dream reports. Three crucial steps of this process will be distinguished: dream production (the generation of a conscious experience during sleep), dream encoding (storing a trace of this experience in memory), and dream retrieval (accessing the memory trace upon awakening). The first part of the paper will assess how major theories think about the relationship between dream reports and these distinct steps. The second part will systematise how trait and state factors affecting dream recall — given different theoretical assumptions - might interact with dream production, encoding and retrieval. Understanding how the distinct steps of dream recall can be modulated by different factors is crucial for getting a better grip on how to acquire information about these steps empirically, and for drawing methodological conclusions with regard to the tools dream research relies on to collect subjective data about dream experiences. The third part of the paper will analyse how laboratory reports, logs and retrospective scales interact with the different factors that affect the distinct steps leading to dream reports, and will argue that prospective methods provide more direct access to data regarding dream production and encoding than retrospective methods, which - due to their inability to provide systematic control over the factors affecting the retrieval stage screen-off the variability in the production and the encoding of dreams.
\end{abstract}

KEYWORDS: dream recall; dreaming; dream experience; encoding; retrieval; trait factors; state factors; methods; prospective and retrospective measures. 


\section{Introduction}

Although the existence of conscious experiences during sleep is not debatable anymore, (Arkin, 1981; Crespin, 2015; Kramer, 2007; LaBerge, 1985; Leclair-Visonneau et al., 2010; Siclari et al., 2017; Valli et al., 2012) since dream mentations can be accessed only via post-awakening reports, there is still an open question regarding the correspondence between dream experiences and dream reports. Do the number and quality of dream reports reliably reflect the experiences subjects undergo while asleep (Windt, 2013)?

On the one hand, there is a distinct group of dreams that show the electroencephalography (EEG) signs of consciousness, yet still cannot be recalled after awakening (Fazekas, Nemeth, \& Overgaard, 2019; Siclari et al., 2017). Some of these might pop into mind later during the day (Cipolli et al., 1992; Domhoff, 1969; Kanzer, 1959), while others can be lost forever. On the other hand, the constructive nature of memory retrieval can produce false memories resulting in reports of never-experienced 'dreams' (Beaulieu-Prévost \& Zadra, 2015; Rosen, 2013). So the route from the actual contents of dreams to dream reports are not straightforward: the reliability of dream recalls as accurate reflections of dream experiences are undermined by both false positives and false negatives.

Moreover, dream recall frequency (DRF), the most often used index for capturing the number of dreams reported from a given time-period, shows extremely high interand intra-personal variance. While some can remember more than one dream per day, others almost never can retrieve any dream (Dement \& Kleitman, 1957; Eichenlaub et al., 2014a; Schredl, 2007, 2018; Siclari et al., 2013). On average, dreams are reported every second morning (Webb \& Kersey, 1967); however, data collection with retrospective methods results in a significantly lower number: around one dream per week (Schredl, 2008, 2009). DRF shows an especially high variance depending on the method used (Aspy, 2016; Bernstein \& Belicki, 1996; Schredl, 2002; Zadra \& Robert, 2012). Nonetheless, there is still a stable trait dimension to be captured independently of measuring tools (Cohen, 1979; Pagel, 2003). High-frequency recallers (grouped by dream recall scales) provide dream reports from $95 \%$ of all rapid eye movement (REM) 
sleep awakenings in the laboratory, while low recallers can recollect experiences from only $46 \%$ of all REM awakenings (Goodenough et al., 1959). Beyond this trait difference, dream recall shows high variability on a case-by-case basis as well (Schredl $\&$ Fulda, 2005a). One of the most relevant factors affecting this variance is the sleep stage before awakening. On average, subjects give reports in $80 \%$ of all cases when awakened from REM sleep, while only around in 50\% when awakened from non-rapid eye movement (NREM) sleep (Nielsen, 2000).

What is the reason behind the discrepancy between the findings of the different methods of measuring dream recall? How can the large intra- and inter-personal differences be explained? Do they reflect a diversity in dream experiences themselves or rather mirror the ability of retaining or retrieving them?

Since dream experiences are not directly available, the same set of data is used independently of whether the aim is to find correlates of dream production or of memory processes, therefore the term 'dream recall' is often used ambiguously. Sometimes it reflects the retrieval of dreams (Tart, 1962; Williamson, Heckel, \& Boblitt, 1970), in other cases, it refers to dream generation itself (Nielsen et al., 2017), while in still other papers it appears as an umbrella term capturing the whole process without separating its steps (Cipolli et al., 2017).

In agreement with Schredl's suggestion (Schredl, 2018), this paper proposes that an important move towards understanding the relation between dream experiences and recalled dreams is to draw attention to the different steps of the process that leads to dream reports. To have a dream report, it is necessary to undergo a conscious experience during sleep (production/generation), retain its memory trace (encoding), and be able to retrieve it at awakening (retrieval). Throughout this paper, the terms 'dream recall' and 'dream reporting' will refer to this whole process.

The goal of this paper is twofold: to offer a review of the literature from this perspective, and to emphasise the methodological consequences of being more reflective about the individual roles of dream production, encoding and retrieval. In Section 2, major theories will be confronted with each other regarding how they think about the relation between dream reports and the different steps of dream recall. Section 
3 will systemise at which of these steps - given different theoretical assumptions the trait and state factors that are known correlates of DRF might exert their effect on the process leading to dream reports. Section 4 will draw methodological conclusions by analysing how the distinct measures of DRF - laboratory reports, dream logs and retrospective scales - modulate these different steps, and by clarifying whether and how the different methods distort the information about dream experiences themselves.

This approach will shed new light on how and to what degree the three steps of dream recall can be responsible for the high variability in DRF between and within subjects. Moreover, it will provide insights into the possible reasons of why DRF is so different depending on the measures used. By concentrating on the building blocks of the complex process of dream recall, this new perspective can help researchers articulate the aims of their investigations as clearly as possible, stay more focused with regard to which step of the process is relevant, and choose the most appropriate measuring tools in order to get the clearest information about the step is question. In particular, in cases where the main aim is to gain a better understanding of aspects of dream generation and encoding, following this approach can help clarify that those methods that are able to control for factors affecting the retrieval stage should be preferred. This paper, thus, can hopefully contribute to breaking the bad habit of preferring retrospective scales of DRF independently of the purpose of the examination. Finally, from a more general perspective, the methodological approach proposed can also be useful for studying all different types of involuntary, stimulus-independent experiences that are hard to capture directly in real time, like mind-wandering and other forms of spontaneous thoughts and imagery.

\section{The relation between dream experience and dream report}

Although the fact that the number of retrieved mentations does not reflect the number of dream experiences accurately is indisputable, there is a disagreement between different approaches about which pre- and post-awakening factors and to what degree are relevant for this discrepancy. Addressing this issue can lead us closer to the understanding of the origin of inter- and intra-personal variance in DRF, i.e. if 
individuals with stable high and low DRF differ in the number or quality of their dreams, or if the variability stems from a difference in their memory skills for encoding or retrieving experiences. The very same question appears in the well-known debate over the interpretation of the diversity in the quantity and quality of reports collected after REM and NREM periods of sleep (Nielsen, 2000): whether there is any stage difference in the encoding and retrieval of the experiences, or sleep stages affect the production of dream mentation itself. The following three sub-sections $(\S 2.1, \S 2.2$, $\S 2.3)$ provide an overview of how different theories think about whether and to what extent it is the production, the encoding or the retrieval of dream experiences that DRF is informative about.

\subsection{DRF reflects dream generation processes}

The theories discussed here emphasise the importance of the quantity or the quality of dream production in determining intra-individual differences in DRF. From their perspective, when the process of awakening is ideal for maximising recall and postawakening factors modulating retrieval are at an optimal level, dream recall accurately reflects the differences in dream production.

\subsubsection{DRF depends on the occurrence of dream generation processes}

According to Hobson's activation-synthesis theory (Hobson \& McCarley, 1977) and AIM model (Hobson, 2014; Hobson, Pace-Schott, \& Stickgold, 2000b), REM processes — such as increased arousal during sleep, aminergic demodulation, and the operation of internal input sources — are responsible for dreaming. Although these different processes do not necessarily occur together, and thus so-called transient or dissociated states can arise, it is a two-generator model (Nemeth \& Fazekas, 2018; Nielsen, 2000) claiming that NREM mentations differ both in their quantity and quality from REM dreams. Whereas during REM sleep the level of activation is high, and internal input source and cholinergic modulation dominate, NREM sleep is characterised by intermediate values along all the three dimensions of the AIM model (activation, internal-external input source, cholinergic-aminergic modulation). In deep NREM sleep 
the brain's activation is on the border of being strong enough to support the occurrence of consciousness (Hobson, 2014).

Moreover, since the relative hypoactivity of the dorsolateral prefrontal cortex (as a result of acetylcholine mediated inhibition of this region) is a common characteristic of sleep (Braun et al., 1997; Dang-Vu et al., 2007; Fazekas \& Nemeth, 2018; Hobson, Pace-Schott, \& Stickgold, 2000a; Hobson et al., 2000b; Hobson et al., 1998; Maquet et al., 1996; Muzur, Pace-Schott, \& Hobson, 2002; Pace-Schott, 2007) forgetting dreams is a general phenomenon irrespective of sleep stages. Therefore, Hobson states (in line with the arousal-retrieval model $(\$ 2.2 .1))$ that an awakening is necessary for retaining the memory of a dream as such awakenings reverse the aminergic demodulation and prefrontal cortical deactivation (Hobson, 2001; Hobson et al., 2000b). However, Hobson also claims that when the process of awakening and post-awakening factors are under control, there is still a major difference regarding dream-recall from different sleep stages. In these cases, the stage difference in DRF mirrors the processes of dream production quite precisely, since the significant variance in the reports of REM and NREM experiences arises from the difference between the distinct generation processes - the low level of dream recall from NREM sleep is mainly due to the low frequency and poor quality (short, thought-like) of the mentations themselves, which are not necessarily defined as dreams by the subject.

\subsubsection{DRF depends on the intensity of dream generation processes}

One-generator models of dreaming (Nemeth \& Fazekas, 2018) are motivated by results indicating that there are only moderate differences between REM and NREM mentations (Cicogna, Cavallero, \& Bosinelli, 1991; Cicogna et al., 2000), and argue that the source of these differences is the fact that the intensity of the process of dream generation varies during sleep (Domhoff, 2018; Foulkes, 1999; Hartmann, 2001).

Sharing this view, Antrobus (Antrobus, 1991, 2000; Wamsley \& Antrobus, 2007) states that not just high, but lower arousal can induce dream production as well, but it is not enough to switch higher-order cognitive processes (the so-called constructive module) on. Weaker elaboration leads to lower recallability of NREM mentations, which then explains the variance in DRF from REM and NREM sleep. 
While Antrobus (2000) emphasises the intensity of dream production and its link to the level of arousal, others argue for a multi-dimensional view with regard to the quality of dreams and the underlying neural processes (Nemeth \& Fazekas, 2018). According to this approach, the quality of conscious experiences can vary along multiple dimensions, such as the intensity, precision and temporal stability of contentspecific neural representations (Fazekas \& Overgaard, 2016, 2018). What matters, form this point of view, then, is that dream production is determined not by the overall level of arousal but rather by local features like neural activity in content-specific areas. In addition, this view claims that the features of dream production have a direct influence on the efficiency of the encoding of the corresponding dream experience, and thus they have a major impact on its recallability (Fazekas et al., 2019).

Cohen (1974b) arrives at similar conclusions. He postulates that DRF reflects the quality of the dream experience. Dream saliency (greater novelty, bizarreness, sensory intensity, number of activities, emotionality) correlates with autonomic activity (eyemovement, breathing rate and irregularity) during sleep that might be a sign of augmented dream production processes. Intensified dream experiences lead to more effective encoding and therefore to greater recallability (Cipolli et al., 1993). The first results supporting this so-called saliency theory demonstrated that the dreams of frequent recallers were more salient, than those of poor recallers (Cohen, 1974b; Cohen \& MacNeilage, 1974). Saliency is also an important factor in the re-recall of once reported dreams (Cipolli et al., 1993; Hartmann, 2008; Trinder \& Kramer, 1971). The mechanism described by the saliency theory is also supported by the findings that high recallers, in general, have greater ability to visualise (form vivid, clear and controllable mental images) in wakefulness as well. This capacity might contribute - via intensified dream images - to better retrieval (Hiscock \& Cohen, 1973). This view is also in line with modern approaches (Kensinger, 2009) demonstrating the impact of emotions and vividness on memory encoding and consolidation (and less conclusively on retrieval processes: Buchanan, 2007; D'Angiulli et al., 2013).

Irrespective of the difference in what they think about the number of relevant dimensions of the dream generation process, these approaches agree that the high 
variability that dream production shows during sleep is not entirely determined by the stages of sleep (Nemeth \& Fazekas, 2018). These theories emphasise that the intensity of dream production is the most significant factor affecting dream recall, moreover it is able to modulate the encoding and retrieval of the experience as well, as a lower quality dream image can be encoded less effectively and/or is harder to be retrieved.

\subsection{DRF reflects the encoding of the perceived experiences}

The theories discussed below hypothesise that the encoding of dreams can vary independently of the intensity of dream production, and thus it is a more important factor of determining dream recall than dream generation itself. DRF, thus, cannot provide faithful information about dream production - especially not in the case of awakening from NREM sleep, as memory encoding and stabilisation often fail in NREM. Different proposals disagree with regard to whether what is necessary for the retaining of a dream experience is a general global increase in brain activity or rather just a local increase in specific regions. Hence there is a disagreement about the exact timing of these memory processes: while some claim that awakenings are necessary for them, others think that they can happen during sleep.

\subsubsection{Global activation of the brain is necessary for dream encoding}

According to this group of theories, the distinction in DRF between awakenings from REM and NREM stages of sleep is due to stage differences in the encoding of dream experiences.

The most famous theory of dream recall that first drew attention to the importance of the memory formation step of dream recall was the arousal-retrieval model (Goodenough, 1991; Koulack, 1991; Koulack \& Goodenough, 1976). It states that the stabilisation of a dream memory depends on the level of arousal. For creating and retaining memory traces it is necessary to awake during or right after the experience. Since in the REM stage the brain is in a more activated state than during slow-wave sleep, the awakening threshold is low and spontaneous awakenings happen easily, especially in the second half of the night (Åkerstedt et al., 2002; Rechtschaffen, Hauri, \& Zeitlin, 1966). Memory formation thus happens more often, which leads to more 
successful dream recall from REM than from NREM sleep, and from late night than from the first cycles of sleep. Additionally, since awakening from slow-wave sleep is slower and more gradual (the sleep inertia is more intense) than from NREM1 and REM (Tassi \& Muzet, 2000), memory processes might be less effective after deep sleep (Schredl, 2018). This theory does not reflect on the possible differences in dream generation between sleep stages. It only emphasises that for the formation and retention of dream memories REM sleep provides a more appropriate background than NREM sleep.

Conduit's attention based model (Conduit, Crewther, \& Coleman, 2000; Conduit, Crewther, \& Coleman, 2004) goes further arguing that there is no evidence to reject the null hypothesis that both the quantity and quality of dream generation are identical in REM and NREM. According to this view, the only difference occurs in the encoding phase, as in REM sleep higher arousal increases attentional awareness which is required for creating memory traces. This hypothesis is claimed to be supported by a diverse set of PET and EEG findings, like the appearance of P300, the occipital EEG alpha decrease, the increase of dopamine release, the hippocampal theta activity, and the enhanced parietal-temporal-occipital (PTO) activity in REM sleep, as these can reflect more intense attentional processes (Conduit et al., 2000). However, many of these findings can have alternative interpretations, for instance, they could equally be seen as signs of enhanced dream production (Fazekas \& Nemeth, 2018).

Some new approaches share the idea that dream recall depends mainly on attentional processes due to their contribution to the encoding of dream experiences (Eichenlaub et al., 2014b). High recallers show significantly higher regional cerebral blood flow in the temporoparietal junction (TPJ) and in the medial prefrontal cortex (MPFC) during wakefulness and even during sleep (in REM in both area, in NREM3 only in the TPJ) than low recallers (Eichenlaub et al., 2014b). Higher activity in the TPJ is associated with higher brain reactivity to the environment during sleep and wakefulness (Eichenlaub et al., 2014a), which, via a greater number of longer intrasleep awakenings, leads to the better encoding of the experiences (Vallat et al., 2017). 
However, as the authors themselves emphasise (Eichenlaub et al., 2014b), this is not the only adequate interpretation of these results. Since the implicated areas are parts of the default mode network (Domhoff, 2018; Domhoff \& Fox, 2015; Fox et al., 2015), it is also possible that the differences between low and high recallers stem from a difference in the capacity to produce intense mind-wandering and dreaming (Mason et al., 2007; Solms \& Turnbull, 2002) — in which case the results would be relevant not for dream encoding but for dream generation (\$2.1.2).

\subsubsection{Local activations are responsible for dream encoding}

Comparing white dreams (when subjects are certain that they had a dream but are unable to recall any content) with contentful dreams and no dreams, Siclari and colleagues (Siclari et al., 2017) argue for a distinction between the neural correlates of consciousness and the memory processes necessary for the recall of the content of experiences. Their findings show that conscious experiences can occur in slow-wave sleep as well, and their occurrence depends on local decrease in the delta activity-range in the posterior hot zone (low- and high-level sensory areas, precuneus, posterior cingulate, retrosplenial cortex) independently of sleep-stages (this evidence is also confirmed by Scarpelli et al., 2017). Additionally, they claim that while local high frequency $(20-50 \mathrm{~Hz})$ activity over the posterior hot zone determines the content of dreams, an increase in high frequency activity over medial and lateral frontal areas are responsible for memory formation and storing (Siclari et al., 2017). As the results show, both conscious experiences and memory processes occur independently of sleep-stages; their frequency, however, is not constant across sleep stages: they occur fewer times (fewer conscious experience, and from those fewer recalled content) in NREM2 and in NREM3 sleep than in REM or NREM1 sleep (Siclari et al., 2013). These findings - in

line with the arousal-retrieval model - demonstrate that increased brain activity is necessary for successful dream recall, but - contrary to the arousal-retrieval model they decompose the process of successful dream recall and specifically address its subcomponents by differentiating between the possible neural underpinnings of dream generation and memory-production. 
While the view that dream encoding is underlain by local brain activations during sleep (and thus a global increase in arousal is not necessary for memory formation) is also shared by others (Cipolli et al., 2017; Esposito, Nielsen, \& Paquette, 2004; Marzano et al., 2011; Scarpelli et al., 2015; Takeuchi et al., 2003), they emphasise the decrease of alpha activity over the temporo-parietal lobe in NREM, and less intensively in REM (Esposito et al., 2004; Marzano et al., 2011), and the increase of frontal theta activity in REM (Marzano et al., 2011) as the correlates of successful dream encoding.

\subsection{DRF reflects the availability of the encoded experience}

Many theories focus on the post-awakening stage of dream recall. The situational interference hypothesis (see $\$ 3.2 .2$ for more detail) aims to define the most optimal setting for dream-retrieval. Others emphasise the relevance of motivation and attitudinal factors (\$3.1.4) in having an influence on the last step of dream recall, whereas the lifestyle hypothesis $(\S 3.1 .3)$ tries to identify the personality traits that might affect dream retrieval. The repression theory $(\$ 3.2 .3)$ also states that the variability of DRF derives (at least partly) from differences in the capacity to retrieve the perceived experience, as according to its central claim, although most of the dreams are encoded they are still not consciously available for the subject after awakening (Anderson \& Green, 2001; Koukkou \& Lehmann, 1983; Solms \& Turnbull, 2002) due to 'retrieval-induced forgetting' (Anderson \& Spellman, 1995).

These approaches are not aimed to define the relation between production, encoding and retrieval, nor do they deny that state or trait differences might exist and have an impact on the quality or quantity of dream production or on the encoding of dreams. They simply emphasise the relevance of post-awakening state and trait factors as an important but not the only source of influence on dream reporting (Goodenough, 1991). They only state that under some circumstances (see §3.2) or in the case of certain people with special characteristics (see §3.1), DRF neither mirrors dream generation appropriately, nor reflects encoding faithfully, as it is highly distorted by the problems of retrieval. 
The functional state-shift model (Koukkou \& Lehmann, 1983) goes much further by proposing that dream production and encoding happen throughout the night, so we experience dreams and also retain information about them independently of sleepstages. However, according to the central claim of this approach, in lower functional states of the brain information is stored in a form, which is not accessible for higher functional states. This claim is supported by the phenomenon of asymmetrical statedependent recall (Overton, 1979): whereas memories formed in a state with a higher level of arousal can be recalled in states with a lower level of functioning, memories formed in a lower level of arousal are only recallable in a similar state. As REM sleep is a state with a high level of arousal (similar to wakefulness) experiences from this stage are in general more accessible after awakening. In the case of NREM sleep, which usually is a state with a lower level of arousal than waking, only a transient period of awakening during or immediately after NREM dreaming can 'elevate' the memories to a higher level of storage, making them available from the wakeful state (Koukkou \& Lehmann, 1983). Without an immediate awakening, although NREM dreams are experienced and encoded (just like those occurring in a REM stage), but won't be available for later recall.

\section{Factors affecting dream recall}

Traditionally, variables predicting dream recall are divided into trait and state factors (Schredl, 2007, 2018; Schredl \& Montasser, 1996/1997). However, differentiating between effects of trait and state factors are not always straightforward, as both actual situational factors and stable trait-like dispositions have some effect on almost every measure (Steyer et al., 2015).

Different investigations use different time scales: serial awakening paradigms rely on seconds before awakenings, more traditional EEG studies focus on periods of time specific to distinct sleep stages, other methodological approaches concentrate on onenight measures of sleep-parameters, and some studies targeting habitual characteristics use questionnaires to summarise data over weeks, months or years. While focusing on short periods (seconds, minutes) or sleep stages is meant to determine state factors, and 
questionnaires measuring habitual characteristics are usually used to capture the effects of trait variables, one-night measures of sleep parameters are used in both cases: in some studies these are used as being informative of state (Schredl, 1995; Taub, 1970) whereas in others as being informative of trait effects (Pagel \& Shocknesse, 2007; Vallat et al., 2017). Although the trait-like characteristics of sleep EEG is well-documented (Ambrosius et al., 2008; De Gennaro et al., 2008; Tarokh, Carskadon, \& Achermann, 2011), this is not the case with all physiological variables that can affect dream recall (Bei et al., 2016; Knutson et al., 2007; Mezick et al., 2009), which renders it unclear whether one-night laboratory measures are able to inform us about stable characteristics.

While DRF in the context of focusing on the relationship between trait factors and dream reports is typically measured by using questionnaires, in the context of trying to capture the relation between state factors and dream reports it is mostly determined by using laboratory awakenings. Dream logs, although offer an alternative way to measure the effects of trait factors on dream recall, are only rarely used due to their resourceintensive nature (see $\S 4)$.

As it will be argued in the next sections, grouping factors as state versus trait variables is not the only way to evaluate them. Considering how different factors affect distinct steps of dream reporting might provide a new and valuable approach to choosing the right measuring tool that matches one's purpose more adequately (see $\S 4$ ). This section reviews the most popular trait and state variables discussed in the literature, and summarises (in Table 1 and Table 2, respectively) the possible effect-mechanisms through which they might have an impact on dream reporting.

\subsection{Trait variables affecting dream recall}

DRF shows a stable gender difference: women remember their dreams more often than men (Schredl, 2008, 2010; Schredl \& Reinhard, 2008b). The number of dream reports seems to show a descending trend during the life span with two peeks on the curve at young adulthood, and at around age 60 (Nielsen, 2012; Schredl, 2008). Still, there are relatively stable interpersonal differences regarding DRF. Depending on the method and 
the retest time interval (between 4-19 weeks), dream recall shows medium to high retest reliability (r=0.59-0.906) (Bernstein \& Belicki, 1996; Cohen, 1969; Schredl, 2004; Schredl \& Fulda, 2005b; Schredl et al., 2001). However, there is no data on dream recall stability on longer (years, decades) time periods. The trait factors, which are meant to be responsible for individual differences in dream recall are the stable characteristics of sleep physiology and brain activity, cognitive abilities, personality traits, and variance in attitude towards dreams.

As summarised in Table 1, these trait factors affect the number of dream reports in different ways: some of them influence dream production itself, others interact with memory encoding, still others have an impact on retrieval. Some factors can have an effect on more than one step of the process that leads to dream recall (Blagrove, 2007; Blagrove \& Pace-Schott, 2010).

\subsubsection{Trait characteristics of sleep physiology and brain activity during sleep}

Habitual sleep duration. Longer habitual sleep duration is often hypothesised to increase dream recall. Antrobus and colleagues (Antrobus, Dement, \& Fisher, 1964) found a weak but significant difference between home reporters and non-reporters in the total amount of time spent is REM-sleep obtained in the laboratory for two consecutive nights. This could not be replicated by Pagel and Schocknesse (2007), who used a onenight measure of sleep parameters (e.g. total sleep time, time spent in REM, number of awakenings) and questionnaire-based DRF. It is, however, debatable whether these onenight sleep parameters can be treated as real trait variables, and whether they are informative with regard to the sleep habits of the subjects. The subjective estimation of habitual sleep duration on questionnaires or by using the average of the daily estimations of diaries is a more trait-like variable, but as results show, it has no or only negligible effect on DRF (Blagrove \& Akehurst, 2000; Schredl \& Fulda, 2005a; Schredl \& Reinhard, 2008a). Trying to understand how habitual sleep duration might influence the number of recalled dreams reveals a complex relationship characterised by possible interactions with different steps of the process. On the one hand, more habitual sleep, by increasing the time spent in REM and light sleep stages, can affect dream generation itself. On the other hand, by leading to more awakenings, it might have a direct 
influence on the encoding step. Moreover, due to resulting in a higher number of experiences from high-level functional states, it can even be seen as a factor affecting dream retrieval.

Sleep quality. In line with the arousal-retrieval model, beyond sleep duration, poor sleep quality - via the increased number of awakenings - could also lead to a higher number of dream reports by interacting either with the encoding or the retrieval step of the process. However, this hypothesis could not be reinforced by laboratory studies (which were derived from only one-night data: Pagel \& Shocknesse, 2007). Moreover, questionnaire-based investigations resulted in controversial findings (Brand et al., 2011; Schredl et al., 1998; Schredl et al., 2003b) not allowing for drawing overarching conclusions. Nevertheless, this result is unsurprising, given that although the subjective estimation of the quality of sleep in the morning mirrors the actual laboratory indexes of sleep-efficiency, the number of awakenings and also the total wake time quite well (Keklund \& Åkerstedt, 1997; Rosipal, Lewandowski, \& Dorffner, 2013), responses to questions about the subjects' habitual quality of sleep (and also about the subjects' habitual dream recall, as will be discussed in §4.4) are often distorted by estimation biases.

Brain activity. Looking for further trait factors of dream recall, Eichenlaub and colleagues (Eichenlaub et al., 2014a) pointed out that the regional cerebral blood flow in TPJ and MPFC is different between the groups of low and high recallers. There is a distinction between these groups in the response to evoked potentials (Eichenlaub et al., 2014a), and in the frequency of awakenings that last at least 1 minutes as well (Vallat et al., 2017). These factors can affect both the intensity of dream production (\$2.1.2) and the probability of transferring memory from short-term to long-term storage (§2.2.1). In addition, if Koukou and Lehman's state-shift theory (Koukkou \& Lehmann, 1983) is correct (§2.3), then frequent and longer awakenings might also influence the accessibility (retrieval) of the stored information as well. However, due to the betweensubject design employed in these studies, it is, again, controversial whether these differences reflect stable characteristics. As De Gennaro and Ferrera (2017) and Scarpelli and colleagues (Scarpelli et al., 2015) emphasise, the existence of trait-like 
characteristics in brain activity or in morphologic-anatomic measures in relation to dream recall is still questionable.

\subsubsection{Stable cognitive factors}

Memory performance. Given the fact that in order to report a dream, memory processes are undoubtedly needed, the idea that the capacity for storing and retrieving experiences might interact with DRF is pretty straightforward. However, the results regarding the existence of trait-like memory skill differences in the explanation of interindividual differences in DRF are insufficient so-far. Whereas Butler and Watson (1985) and Schredl, Frauscher and Shendi (1995) both reported a correlation between visual memory performance and dream recall, others could not replicate these findings (Cohen, 1971; Eichenlaub et al., 2014b). It has also been argued that beyond visual memory performance the capacity to remember personal events (autobiographical memory) might also count as a trait variable that affects dream recall (Nielsen, 2012; Robbins \& Tanck, 1978; Sehulster, 1981). At the neural level, awake memory performance is correlated with theta synchronisation and alpha desynchronisation (Mölle et al., 2002). Theta activity increases both during the encoding phase (Klimesch et al., 1996; Klimesch et al., 1997) and during the retrieval of previously studied information (Klimesch et al., 2001; Klimesch et al., 2006). In line with the view that mechanisms of episodic memory encoding and retrieval are the same along different states of consciousness, it has been repeatedly demonstrated that frontal theta power might be seen as a — state — factor that determines dream encoding (\$2.2.2). Theta oscillations have also been suggested to be trait factors of waking episodic memory performance (Addante et al., 2011; Cohen, 2011; Guderian et al., 2009). In parallel with this, Fell and colleagues (Fell et al., 2006) demonstrated that values of medio-temporal connectivity in waking state and NREM and REM sleep differentiate between good and bad dream recallers (measured over awakenings in one laboratory night), which might be considered as a trait difference leading to inter-individual differences in dream recall capacity. However, as the authors themselves and others emphasise, further data are needed in order to prove this hypothesis (De Gennaro \& Ferrara, 2017; Fell et al., 2006). 
IQ. With regard to the relationship between dream recall and intelligence, the findings are inconsistent. While some studies find no correlation between IQ and dream recall (Hill, 1974), others show that high performance scores on the Block design of Wechsler scales correlate with high recall capability in childhood and adolescence (Foulkes, 1985). Since this performance did not correlate with memory skills, Foulkes (1999) claims that it affects, via enhanced visual imagination, dream production itself.

\subsubsection{Personality traits}

Imagination, absorption, fantasy proneness. Intense visual imagination, absorption, fantasy proneness and dissociation are the most promising candidates for trait factors that have an influence on DRF. People characterised by these traits are hypothesised to have more salient, more vivid dreams, which, then, in line with the salience theory, would explain why they can recall their dreams more easily (Giesbrecht \& Merckelbach, 2006; Levin \& Young, 2001-02; Watson, 2003) implicating that these factors exert their effects on dream reports by having an impact on the quantity and quality of dream production. This claim, however is debated as others have argued that imagination, absorption and fantasy proneness primarily interact not with dream generation but with retrieval via attitudinal and motivational factors and via estimation biases affecting the retrospective assessment of one's DRF (see below; BeaulieuPrévost \& Zadra, 2007; Levin, Fireman, \& Rackley, 2003).

Boundary thinnes. Boundary thinness (degree of separation of intra-psychic components of the mind) is another important variable, that can affect the bizarreness, emotionality and vividness of dreams, and can even make experiences more accessible from different states of consciousness (Hartmann, Elkin, \& Garg, 1991; Kunzendorf et al., 1997; Schredl, Kleinferchner, \& Gell, 1996).

Inner-life acceptance style. Focusing on personality factors, Schonbar (1965) claims that frequent dream recalling is part of a so called inner-life acceptance personality style, which is characterised by openness to experience, divergent thinking, creativity, intense imagination, field-independence, inner locus of control, introspection, and tendency to cope with anxiety, instead of repressing feelings. 
Although several studies provided support for the correspondence between these personality variables and DRF (Brand et al., 2011; Goodenough et al., 1974; Schredl et al., 2003a; Schredl, Jochum, \& Souguenet, 1997; Tart, 1962; Watson, 2003; Williamson et al., 1970), others found no such correlations (Blagrove \& Akehurst, 2000; Bone, Nelson, \& McAllister, 1970; Cohen, 1974b; Cohen \& Wolfe, 1973; Levin et al., 2003; Schredl et al., 2003b). Furthermore, the majority of the results are weak, and cannot provide information about the direction of the hypothesised causal relationship. The contradictory findings are mostly due to methodological issues regarding how to measure DRF (see §4). While scale-based measures found notable relationships between the traits in question and DRF, log-based measures revealed much weaker correlations. This means that although these personality traits might influence DRF by affecting the salience of dreams, they most likely correlate with modulations of retrieval via estimation biases (tendency for retrospective under- or overestimation; BeaulieuPrévost \& Zadra, 2007; Levin et al., 2003) and via their co-occurrence with attitudinal (see §3.1.4) and motivational (§3.2.2) factors (Blagrove, 2007; Blagrove \& Pace-Schott, 2010).

\subsubsection{Attitude towards dreams}

The concept of 'attitude towards dreams' captures the subjects' interest in and motivation to concentrate on their dreams. Therefore, unsurprisingly — by facilitating the retrieval of dream experiences - it shows a consistent relationship with DRF, and an even stronger relationship with the personality traits discussed above (Schredl \& Göritz, 2017). As Schredl and colleagues (Schredl et al., 2003b) propose, attitude towards dreams may mediate between personality variables and DRF (although the direction of causality between these factors is unclear). However, the level of correlation between attitude towards dreams and DRF falls drastically when DRF is measured by diaries. Consequently, attitude towards dreams might at best only slightly correlate with the capacity of dream reporting, and could rather exert significant influence, via attention and estimation biases, on the answers subjects provide to the questions of retrospective scales (Beaulieu-Prévost \& Zadra, 2005; Beaulieu-Prévost \& Zadra, 2007). 
Table 1

Trait variables affecting DRF

\begin{tabular}{|c|c|c|c|}
\hline TRAIT variables & GENERATION & MEMORY ENCODING & RETRIEVAL \\
\hline $\begin{array}{l}\text { longer habitual } \\
\text { sleep duration }\end{array}$ & $\begin{array}{l}\text { more dreaming due to more } \\
\text { REM processes }(\S 2.1 .1) \text {, or } \\
\text { more intensified dreaming due } \\
\text { to more periods of higher } \\
\text { brain activity }(\S 2.1 .2)\end{array}$ & $\begin{array}{l}\text { more awakening from more } \\
\text { REM and more light sleep } \\
(\S 2.2 .1)\end{array}$ & $\begin{array}{l}\text { easier access to information } \\
\text { due to more high-level } \\
\text { functional states }(\S 2.3)\end{array}$ \\
\hline $\begin{array}{l}\text { poor habitual } \\
\text { sleep quality }\end{array}$ & & $\begin{array}{l}\text { more awakening due to } \\
\text { poor sleep quality (§2.2.1) }\end{array}$ & $\begin{array}{l}\text { easier access to information } \\
\text { from states interrupted by } \\
\text { awakening due to elevating } \\
\text { memories to higher order } \\
\text { storage (§2.3) }\end{array}$ \\
\hline $\begin{array}{l}\text { enhanced } \\
\text { activation of } \\
\text { TPJ and MPFC }\end{array}$ & $\begin{array}{l}\text { tendency to intensive imagery } \\
\text { due to enhanced activity of } \\
\text { the DMN }(\S 2.1 .2)\end{array}$ & $\begin{array}{l}\text { more awakening due to } \\
\text { enhanced brain reactivity } \\
(\S 2.2 .1)\end{array}$ & $\begin{array}{l}\text { easier access to information } \\
\text { from higher level functional } \\
\text { states due to higher arousal or } \\
\text { due to more frequent } \\
\text { awakenings }(\S 2.3)\end{array}$ \\
\hline memory & & $\begin{array}{l}\text { higher medio-temporal } \\
\text { connectivity }(\S 2.2 .2)\end{array}$ & $\begin{array}{l}\text { higher medio-temporal } \\
\text { connectivity (\$2.2.2) }\end{array}$ \\
\hline $\begin{array}{l}\text { IQ (Block Design } \\
\text { Test) }\end{array}$ & $\begin{array}{l}\text { enhanced visual imagination } \\
\text { due to better visuospatial } \\
\text { skills (§2.1.2) }\end{array}$ & & \\
\hline $\begin{array}{l}\text { absorption } \\
\text { fantasy-proneness } \\
\text { dissociation }\end{array}$ & $\begin{array}{l}\text { more intense dreaming - } \\
\text { saliency (§2.1.2) }\end{array}$ & & $\begin{array}{l}\text { positive attitude towards } \\
\text { dreams and increased } \\
\text { motivation }(\S 2.3)\end{array}$ \\
\hline boudary thinnes & $\begin{array}{l}\text { affects bizareness and } \\
\text { vividness of dreams (\$2.1.2) }\end{array}$ & & $\begin{array}{l}\text { information is more accessible } \\
\text { between distinct states of } \\
\text { consciousness }\end{array}$ \\
\hline $\begin{array}{l}\text { "inner-life } \\
\text { acceptance" } \\
\text { style traits }\end{array}$ & $\begin{array}{l}\text { more intense dreaming - } \\
\quad \text { saliency }(\S 2.1 .2)\end{array}$ & & $\begin{array}{l}\text { positive attitude towards } \\
\text { dreams and increased } \\
\text { motivation }(\S 2.3)\end{array}$ \\
\hline $\begin{array}{l}\text { positive attitude } \\
\text { towards dreams }\end{array}$ & & & $\begin{array}{c}\text { more awareness to dreams } \\
\text { due to higher motivation (\$2.3) }\end{array}$ \\
\hline
\end{tabular}

Note. The hypothesised ways in which previously studied trait variables correlating with DRF enter the process of dream recall, and influence the number of dream reports (with reference to parts of $\S 2$ where the theoretical background assumed is discussed). 


\subsection{State variables affecting dream recall}

Since the effects of trait variables on DRF are quite small and controversial (and highly affected by the chosen method of measuring DRF), the conclusion in the literature is that state factors are the main determinants of dream recall (Blagrove, 2007; Blagrove \& Pace-Schott, 2010; De Gennaro \& Ferrara, 2017; Levin et al., 2003; Scarpelli et al., 2015).

There is a large intra-individual fluctuation on a case-by-case basis in reporting dreams. State characteristics of the preceding sleep or sleep stage, situational factors at the moment of awakening, and life events and stressors affecting different steps of the dream recall process can all be responsible for this high variability.

\subsubsection{State variables of sleep physiology and brain activity during sleep}

Sleep duration. Sleep duration, used as a state factor, is a better predictor of dream recall than habitual sleep duration (Schredl \& Fulda, 2005a; Schredl \& Reinhard, 2008a). With more and more time spent in sleep the number of reported dreams increases (Schredl \& Reinhard, 2008a; Taub, 1970). This effect might be due to more and longer REM periods, more intra-sleep awakenings, or post-awakening factors like sleep inertia, which is more pronounced when sleep duration is below average (Trotti, 2017). Since one night sleep duration can possibly influence dream recall in all these different ways, as a concept it is too broad to be able to differentiate between the different steps of the process that leads to dream recall. A more informative approach in this respect would be to distinctively focus on all those factors that change with sleep duration.

Sleep stages. The sleep stage preceding awakening is one of the most robust indicator of dream reporting. While $80 \%$ of all awakenings from REM lead to dream recall, only 50\% do so when waking from NREM sleep (Nielsen, 2000). However, the interpretation of this result is still not straightforward. It might be a consequence of the differences regarding the number or qualities of dreams produced in the different sleep stages (\$2.1). The REM stage, due to more spontaneous awakenings, can also interact with the step of memory encoding (\$2.2). Moreover, easier access to experiences 
occurring in the REM stage can result in an impact even on dream retrieval $(\S 2.3)$. Reduced sleep inertia associated with awakening from REM sleep, can also interact with both the encoding (in accordance with those theories that claim that encoding happens at the time of awakening, see §2.2) and the retrieval steps (as increased cognitive performance right after awakening from light and REM sleep might promote attention and motivation thereby facilitating retrieval; Tassi \& Muzet, 2000; Vallat et al., 2017).

Autonomic activities during sleep. Autonomic activities (breathing rate, irregularity of breathing, eye-movement density) during REM and NREM sleep are also hypothesised to be state factors that correlate with dream recall. According to the salience hypothesis $(\S 2.1 .2)$, this correlation is due to the characteristics of dream production, which act as a common cause: the intensity of the dream content (its vividness, emotional tone, etc.) induces these physiological reactions, and, at the same time, enhances the efficiency of the encoding of the experience. Nevertheless, the causal relationship between these variables are still debated, and the results are inconclusive (Goodenough, 1991).

Brain activity during sleep. As discussed above (\$2.2.2), recent studies have attempted to identify those neural state characteristics that uniquely correlate with dream production and dream encoding. Siclari and colleagues (Siclari et al., 2017) reported high-frequency $(20-50 \mathrm{~Hz})$ posterior hot zone activity as the neural signature of dream production and high-frequency activity in the medial and lateral frontal areas as pre-awakening EEG signs of memory processes. Others identified a decrease in alpha activity over the temporo-parietal lobe (Cipolli et al., 2017; Esposito et al., 2004; Marzano et al., 2011; Scarpelli et al., 2015; Takeuchi et al., 2003) and increased frontal theta activity (Marzano et al., 2011) as the correlates of better dream encoding.

\subsubsection{Situational interference, motivation and attention}

Situational interference and abrupt awakenings. The interference theory (Cohen \& Wolfe, 1973), focusing on the relevance of awakening (Shapiro et al., 1965) and situational factors (Cohen \& Wolfe, 1973), emphasises that memories of dreams can easily be displaced by distracting thoughts or tasks upon awakening. While the slightest 
distraction (like listening to weather forecast) or delay can disrupt memory retrieval drastically (see Cohen \& Wolfe (1973) for a now classical study; and Parke \& Horton (2009) for a recent replication), abrupt awakenings enhance dream reporting especially for infrequent recallers (Parke \& Horton, 2009; Shapiro et al., 1965). A sudden awakening (contrary to a gradual one), thus, seems to reduce the chance of being distracted by concurrent tasks, and thereby maintains access to the memory trace of the dream (Parke \& Horton, 2009). Abrupt awakenings by inducing immediate and intensive enhancement of arousal, might even influence the formation and retainment of a memory trace as well (Schredl, 2018) - if this transfer occurs at awakening as suggested by the arousal-retrieval model (Koulack \& Goodenough, 1976; see §2.2.1) and some more recent experimental approaches (Vallat et al., 2017).

Motivation. The subjects' motivation to catch a dream is also a significant factor of dream reporting, as it has been robustly demonstrated by several experiments that manipulated the instructions for morning dream recall or the context of dream recall questionnaires (Aspy, 2016; Cohen \& Wolfe, 1973; Halliday, 1992; Schredl, 2002; Schredl et al., 2001). The motivation to remember dreams, by enhancing the subject's attention to and concentration on the dream, decreases situational interference and therefore leads to a higher level of recall.

\subsubsection{Life events and stressors}

Life events, psychological and physical well-being or stressors show robust correlations with dream features, such as emotionality, bizarreness, intensity or complexity (Bódizs et al., 2008; Hartmann \& Brezler, 2008; Hartmann et al., 2001; Najam et al., 2006; Pesant \& Zadra, 2006; Punamäki, 2007; Zadra \& Donderi, 2000), and less conclusively with DRF as well (Bódizs et al., 2008; Cartwright, 2005; Hill, 1974; Punamäki, 2007). However, the direction of causality between such psychological factors and the qualities of dreams are highly questionable (Blagrove \& Fisher, 2009; Bódizs et al., 2008; Zadra \& Donderi, 2000).

It is also debated what those characteristics of dreams might be that lead to better recallability. Freud (1964/1900), for instance (see also Vedfelt, 1999), states that the high intensity of latent wishes compel the repression of dreams, and therefore lead to 
forgetting. Psychoanalytic approaches are indecisive regarding whether intensified latent wishes caused by different life situations lead to the modulation of dream production itself. Their focus is on repression, which is the prevention of retrieval (of dreams that might have been successfully encoded and have a further impact on the subject's behaviour; see $\S 2.3)$.

The salience theory (Cohen \& MacNeilage, 1974) emphasises the exact opposite: more salient dreams (more intensified dream generation), due to richer encoding, have higher chance to be recalled after awakening. This entails that the quality of dream production has an influence on DRF - via determining the process of encoding $(\S 2.1 .2)$.

Since it is impossible to compare the characteristics of never recalled dreams with successfully retrieved ones, there are only indirect results available to understand the relation between different dream qualities and DRF. Studies aimed to test the assumption that stressors have an impact on dreams via laboratory manipulations of subjects' emotions before sleep yielded controversial results reporting either enhanced or diminished dream recall (Baekeland, 1971; Cohen, 1974a; Foulkes et al., 1967; Foulkes \& Rechtschaffen, 1964). Findings regarding the relationship between natural life-situations (divorce, bereavement, different kinds of traumas) and variations in DRF are also ambivalent (Arkin et al., 1976; Cartwright, 1996; Najam et al., 2006; Rofe \& Lewin, 1979; Valli et al., 2006). This inconsistent set of data probably reflects a complex relation between awake emotional state, dream content and recall. There might be plenty of factors that can influence this connection, like the intensity of awake emotions, personality traits, or even the gender of the dreamer (Armitage, 1992; Blagrove \& Akehurst, 2000; Punamäki, 2007).

While the modern approach of neuro-psychoanalysis (Solms, 2000a, 2000b) has difficulties with understanding censorship in terms of neuroscience (Hobson, 2001), and struggles with identifying the mechanism of repression in physiological terms (Solms \& Turnbull, 2002), the process proposed by the saliency theory is much more consistent with contemporary knowledge regarding the relationship between emotions and memory operations. 
Table 2

State variables affecting DRF

\begin{tabular}{|c|c|c|c|}
\hline STATE variables & GENERATION & MEMORY ENCODING & RETRIEVAL \\
\hline sleep duration & $\begin{array}{l}\text { higher number of dreams due to } \\
\text { more REM processes }(\S 2.1 .1) \text {, } \\
\text { or more intense dreams due to } \\
\text { higher chance of increased } \\
\text { brain activity (§2.1.2) }\end{array}$ & $\begin{array}{c}\text { more awakening from } \\
\text { more light sleep and REM } \\
(\S 2.2 .1), \text { and reduced } \\
\text { sleep inertia after longer } \\
\text { sleep (§2.2.1) }\end{array}$ & $\begin{array}{l}\text { increased motivation and } \\
\text { better cognitive performance } \\
\text { due to reduced sleep inertia }\end{array}$ \\
\hline REM stage & $\begin{array}{l}\text { higher number of dreams due to } \\
\text { more REM processes }(\S 2.1 .1) \text {, } \\
\text { or more intense dreams due to } \\
\text { higher chance of increased } \\
\text { brain activity }(\S 2.1 .2)\end{array}$ & $\begin{array}{l}\text { more awakening from } \\
\text { REM }(\S 2.2 .1) \text {, and } \\
\text { reduced sleep inertia } \\
\text { after REM }(\S 2.2 .1)\end{array}$ & $\begin{array}{l}\text { easier access to information } \\
\text { from REM (\$2.3) and } \\
\text { increased motivation and } \\
\text { better cognitive performance } \\
\text { due to reduced sleep inertia }\end{array}$ \\
\hline $\begin{array}{l}\text { autonom activity } \\
\text { under sleep }\end{array}$ & $\begin{array}{l}\text { more intense dreaming - } \\
\text { saliency }(\S 2.1 .2)\end{array}$ & & \\
\hline $\begin{array}{l}\text { local posterior hot } \\
\text { zone activity }\end{array}$ & $\begin{array}{l}\text { opportunity for and content } \\
\text { characteristics of dream } \\
\text { generation (§2.2.2) }\end{array}$ & & \\
\hline $\begin{array}{l}\text { increased } 20-50 \mathrm{~Hz} \\
\text { activity in medial and } \\
\text { lateral frontal areas }\end{array}$ & & $\begin{array}{l}\text { activation of processes } \\
\text { necessary for encoding } \\
(\S 2.2 .2)\end{array}$ & \\
\hline $\begin{array}{l}\text { decreased alpha } \\
\text { activity over the } \\
\text { temporo-parietal } \\
\text { lobe and increased } \\
\text { frontal theta activity }\end{array}$ & & $\begin{array}{l}\text { activation of processes } \\
\text { necessary for encoding } \\
(\S 2.2 .2)\end{array}$ & \\
\hline $\begin{array}{l}\text { situational } \\
\text { interference }\end{array}$ & & & $\begin{array}{l}\text { disrupted retrieval due to } \\
\text { reduced access to memory } \\
\text { trace }(\S 2.3)\end{array}$ \\
\hline abrupt awakening & & $\begin{array}{l}\text { intensified and immediate } \\
\text { arousal-enhancement at } \\
\text { awakening (§2.2.1) }\end{array}$ & $\begin{array}{l}\text { decreased situational } \\
\text { interference }(\S 2.3)\end{array}$ \\
\hline motivation & & & $\begin{array}{l}\text { more awareness to dreams } \\
(\S 2.3)\end{array}$ \\
\hline life events, stressors & $\begin{array}{l}\text { more intense dreaming - } \\
\quad \text { saliency (§2.1.2) }\end{array}$ & & $\begin{array}{l}\text { enhanced tendency for } \\
\text { repression due to intensified } \\
\text { latent wishes }(\S 2.3)\end{array}$ \\
\hline
\end{tabular}

Note. The hypothesised ways in which previously studied state variables correlating with DRF enter the process of dream recall, and influence the number of dream reports (with references to parts of $\$ 2$ where the theoretical background assumed is discussed). 


\section{Methods of measuring DRF}

As shown in Section 3, trait and state factors correlating with DRF can influence the process of dream reporting in multiple ways. In order to clarify the exact mechanisms of their impact, the studied variables on both sides of the hypothesised correlations should be chosen more carefully. On the one hand, instead of the classical broad concepts of trait and state factors (like sleep duration or sleep quality), more rigorously specified variables are needed. On the other hand, both for the operationalisation of dream recall and for choosing the most appropriate measuring tool for capturing DRF it should be carefully considered which step of the dream reporting process is in the focus of the actual study. As I will argue below, the methods available to measure DRF differ not just in terms of their time-scales, but also in terms of how informative they are able to be about the different steps of dream recall. The current domination of questionnaires as a method of collecting information on the trait characteristics of DRF is a manifestation of the ignorance of this latter aspect, as these scales are not able to recover trustworthy information about the pre-awakening steps of dream reporting since they are highly distorted not just by uncontrolled variables at awakening (interacting with retrieval), but even by estimation biases affecting the answers on retrospective scales.

\subsection{Varieties of dream recall}

Although dream recall is the only route to dream experiences, it is not an all-or-nothing kind of phenomenon (Goodenough, 1991). There is a continuum extending from no report at all, through white dreams and dreams with slight impressions or only with a few specific content-elements, to dream stories with complex narratives. Without an insight into the sleeping mind, the question whether these characteristics of the reports reflect dream production, or rather they are consequences of modifications in the memory processes necessary for encoding and retrieving experiences, is unresolved (Fazekas et al., 2019; Feinberg, 2000; Siclari et al., 2017; Windt, Nielsen, \& Thompson, 2016).

For example, while some results (Dement \& Kleitman, 1957; Dement \& Wolpert, 1958; Stickgold, Pace-Schott, \& Hobson, 1994) partly show that the total word count of 
a report correlates with the time spent in a REM stage before awakening — implicating that report-length reflects the length of the dream itself, - others couldn't replicate these findings (Rosenlicht, Maloney, \& Feinberg, 1994). As Rosenlicht and colleagues (Rosenlicht et al., 1994) argue, the number of words used to describe a dream corresponds not with the length of a given sleep stage but rather with prior sleep duration. Since reports after late-night 10-minute REM periods are longer than reports after early-night 10-minute REM periods, Rosenlicht and colleagues (Rosenlicht et al., 1994) claim that report-length is a measure of dream encoding (instead of dream generation) since it depends on the level of arousal, which is higher during late-night REM sleep, and which has known effects on memory processes (Koulack \& Goodenough, 1976). Cipolli and colleagues (Cipolli et al., 2015) add that higher intrasleep arousal might be a sign of elevated cognitive functioning contributing to the generation of more organised dream narratives, which, then, are better retained and easier to recall.

Another phenomenon that raises questions regarding which steps of dream reporting it is informative about is the peculiar case of white dreams. White (contentless) dreams are sometimes categorised as successful dream reports (Herlin et al., 2015) while in other cases they are sidelined as uninformative data (Lewis et al., 1966; Zadra \& Robert, 2012). Siclari and colleagues (Siclari et al., 2017) argue that white dreams are consequences of the failure of dream encoding, which means that they should be merged with contentful dreams if the aim is to explore the correlates of dream production, and that they are most informative with regard to how dream encoding might break down. Others, however, have argued that white dreams correlate with low intensity dream production (Fazekas et al., 2019), implying that they are the results of the modulation of the process right at dream generation, and thus they carry information about the first step of dream recall.

\subsection{Retrospective-logbook disparity: methodological considerations}

Prospective methods - laboratory dream reports and dream logs — are meant to capture dream recall relatively close to the experience. Retrospective measures - 
different kinds of DRF scales - capture a general subjective estimation of DRF referring to a time-interval from the past. There is a moderate to high correlation (between $\mathrm{r}=0.33$ and $\mathrm{r}=0.69$ ) between dream recall measured by these methods (Cohen, 1979; Goodenough et al., 1959; Robert \& Zadra, 2014; Watson, 2003). Nonetheless, the exact number of dream reports, or the number of special kinds of dreams (like nightmares, bad dreams, lucid dreams, dreams with aggressive, friendly or sexual elements) differ significantly when measured by logs or scales (Aspy, 2016; Aspy, Delfabbro, \& Proeve, 2015; Beaulieu-Prévost \& Zadra, 2007; Bernstein \& Belicki, 1996; Robert \& Zadra, 2008; Schredl, 2002; Wood \& Bootzin, 1990; Zadra \& Domhoff, 2017; Zadra \& Donderi, 2000; Zadra \& Robert, 2012). With prospective tools DRF is 3-10 times higher than when measured retrospectively by scales (Cohen, 1969; Redfering \& Keller, 1974).

Additionally, individual differences in DRF assessed by dream logs do not show the same correlations with personality traits that can be found in the case of scalemeasured DRF (Beaulieu-Prévost \& Zadra, 2005; Beaulieu-Prévost \& Zadra, 2007; Bernstein \& Belicki, 1996; Levin et al., 2003; Levin \& Young, 2001-02).

There is no agreement with regard to the possible causes of this so-called retrospective-logbook disparity (Aspy et al., 2015). Two alternative explanations have been proposed: the retrospective underestimation and the logbook enhancement effects.

The claim that there is a tendency to retrospectively underestimate experiences can be derived from the results that people make their estimation about the frequency of past events on the basis of how easily they can recall specific examples of them (Aspy et al., 2015; Tversky \& Kahneman, 1973). Since it is relatively easy for high recallers to remember their dreams, their assessments reflect the real frequency of the experiences quite well. However, if not enough instances of dream memories are available (like in the case of subjects not interested in dreams), people are more vulnerable to estimation biases based on their report style, cognitive representations and personality traits. This might account for the well documented results that retrospective assessments compared to $\operatorname{logs}$ - are more robustly related to attitude towards dreams (BeaulieuPrévost \& Zadra, 2005; Beaulieu-Prévost \& Zadra, 2007), and personality traits like 
psychological boundaries, absorption, openness to experiences (Beaulieu-Prévost \& Zadra, 2007; Hill, Diemer, \& Heaton, 1997), and imaginative involvement and fantasy (Levin et al., 2003; Levin \& Young, 2001-02). The same is true in the case of the relation between nightmare frequency and trait anxiety: this relation is significantly weaker when the index of nightmare frequency is based on log instead of scale measures (Wood \& Bootzin, 1990). The most robust difference between log- and scalebased DRF occurs when the scale focuses on a long time period, as with the increase of the time interval covered it becomes progressively more difficult for subjects to rely on real examples to answer the questions properly (Robert \& Zadra, 2008; Zadra \& Donderi, 2000).

Due to estimation biases and memory defaults as selective recall and embellishment, retrospective scales not only underestimate, but give a massively deformed index of dream recall capacity. Consequently, several authors claim that retrospective one-item scales are inadequate measures of such a highly fluctuating phenomenon like dreaming - especially in the case of subjects who are not interested in and therefore rarely pay attention to their dreams ponder (Beaulieu-Prévost \& Zadra, 2007; Blagrove \& Akehurst, 2000; Levin et al., 2003; Zadra \& Domhoff, 2017).

The other explanation states that, by forcing subjects to focus on their dreams after awakening, dream logs enhance DRF (Aspy, 2016; Schredl \& Montasser, 1996/1997). This approach offers an alternative account of the greater retrospectivelogbook disparity in the case of subjects who are not interested in dreams (Aspy, 2016; Aspy et al., 2015; Cory et al., 1975; Schredl, 2002), since keeping a logbook greatly enhances the motivation and attention of these subjects, while, due to a ceiling-effect, not much enhancement is possible in the case of those who already had high interest in dreams (Aspy et al., 2015). According to this approach, it is the intrusive nature of logs that is responsible for this effect. Logs, therefore, are claimed to be inaccurate reflections of DRF (Aspy et al., 2015).

Note that this second argument is based on the premise that the enhancement effect of logbooks on DRF is an artefact - a distortion of the correct number that can best be approximated by retrospective scales (Beaulieu-Prévost \& Zadra, 2005; 
Beaulieu-Prévost \& Zadra, 2007). However, although the fact that completing a log enhances the number of dream reports (compared to scales) is demonstrated by several studies (Aspy, 2016; Zadra \& Robert, 2012), it does not follow that maximising attentional and motivational factors would degrade the validity of this method.

In fact, as the rest of the paper will argue, the opposite is true: the intensified motivation and attention to dreams, enhanced by logs, improve the quality of the data for studies interested in dream production or the encoding of dream experiences. In what follows, it will be shown that the phenomena of logbook enhancement and retrospective underestimation are both reflections of how the different variables affecting the retrieval step of dream recall influence the outcomes of these two kinds of measurements. Therefore, the main difference between the distinct measures of DRF is how they control for the factors that determine the retrieval of dreams.

\subsection{Prospective methods: laboratory reports and logs}

\subsubsection{Laboratory reports}

The highest percentage of reports are produced after awakenings in the laboratory. This is the only method that is specifically designed to be able to differentiate between REM and NREM mentations, and the only tool that can ensure gaining access to early-night dreams (Zadra \& Domhoff, 2017). With its ability to match neurophysiological data with the presence or absence of a dream report or a specific dream characteristic, it is the only way to get detailed information about the state variables affecting dream production and encoding.

Laboratory awakenings can keep most of the state variables affecting the retrieval step under control, since the awakening process is standard, upon awakenings the subjects are immediately asked about their dreams, and the commitment needed to participate in such a research can maximise the subjects' attentional and motivational efforts to catch their dreams, even if they are generally not interested in following their dream-life. DRF measured by laboratory reports, therefore, is the best indicator of production and encoding processes as it provides information about dream recall capacity in a situation when interference with dream retrieval is close to minimal. 
One of the downsides of this method is that it is the most expensive and timeconsuming one, especially because more nights in the laboratory are necessary to reduce the effect of the unusual environment (Zadra \& Domhoff, 2017). So, even if, by relying on several awakenings (during several nights) in the laboratory, it is possible to estimate the trait-like dream recall capacity of a subject (Goodenough et al., 1959), this method is generally used to collect data from shorter time-intervals, and, therefore, to focus on intra-individual rather than inter-individual differences.

The greatest worry about this method is related to its construct validity, since frequent awakenings might interrupt the natural process of sleep, and thus they might affect the natural mechanisms of dream production and encoding as well. Relatedly, frequent awakenings might generate sleep inertia (Zadra \& Domhoff, 2017) that has a negative effect on dream recall (Schredl, 2018).

\subsubsection{Dream logs}

Although narrative dream logs (diaries) are the most popular tools for examining the contents of dreams, they are rarely used in studies of dream recall. In order to complete a narrative dream log, subjects need to collect and write down their dreams with as many details as possible every morning right after awakening for one or more weeks. When subjects cooperate, this method is able to ensure lower situational interference by directing the subjects' attention to their dreams right after awakening (however, situational factors are not controlled in the same way as in the case of laboratory studies). Moreover, participating in a log study keeps motivation relatively high (even for those who are generally not interested in dreams). Via these effects, this method provides reasonably adequate conditions for retrieval, therefore the individual differences in log DRF can uncover differences in production and encoding quite well. Since after one week the participants' motivation starts to decrease, and becomes drastically reduced by the end of the second week, logs covering a two-week period are best at balancing between collecting enough data and keeping the data valid (Aspy, 2016; Zadra \& Robert, 2012).

Checklist format logs try to solve the problem of diaries, as completing them requires less effort. Participants are asked only to indicate if they had any, and if so, 
then what kind of dreams (chosen from a given list) during the night before. Other kinds of checklists also ask for a title or a short transcription of the dream as well. As previous studies have demonstrated (Robert \& Zadra, 2008; Zadra \& Robert, 2012), the more demanding a method is, the easier it is to loose the motivation for following instructions properly. Therefore, especially in the case of relatively longer periods, checklist dream logs appear to yield more accurate DRF values compared to narrative ones (Zadra \& Robert, 2012).

As we have seen, some accuse this method of being intrusive and leading to distorted data (\$4.2). However, no evidence has been collected so far in support of the claim that dream logs would affect the quality or quantity of dream production or the process of encoding. In fact, contrary to the intrusiveness claim, logs attenuate the impact of those factors that would inhibit dream retrieval. Thus, by preventing interference with retrieval, logs help acquiring more accurate information about dream production and encoding.

Since DRF based on logs are quite stable over time (Schredl \& Fulda, 2005b; Watson, 2003) and correlate with habitual dream recall measured by scales (Schredl, 2002; Zadra \& Robert, 2012), dream logs are good candidates to be valid tools for measuring the trait-like dream recall capacity of a subject. Nonetheless, as it requires much more effort from participants than a one-item scale, it is inevitable that more subjects will leave the study prematurely. However, as shown above and below, its benefits greatly outweigh its costs.

\subsection{Retrospective methods: dream recall scales}

Dream recall scales are the most common methods for capturing inter-individual differences in DRF. Scales can differ in the time-interval they cover, but to decrease retrospective underestimation (§4.2) relying on shorter periods - e.g. a week (Zadra \& Robert, 2012) or using answer-options with mixed time-intervals (Schredl et al., 2014) - are preferred.

Scales are typically used to sort participants into groups of high and low dream recallers. Relying on logs to capture DRF is more the exception than the rule in 
contemporary literature (but see e.g. Zou et al., 2018). Relying on scales for this purpose is the default method even in laboratory studies where the aim is to reveal neurophysiological trait correlates of dream recall (Eichenlaub et al., 2014a; Eichenlaub et al., 2014b; Pagel \& Shocknesse, 2007; Vallat et al., 2017). This is the quickest and cheapest way of acquiring information about general DRF, since only a single question is needed to be answered. It even has good test-retest reliability (Schredl, 2004).

However, scales have major limitations that question their validity (BeaulieuPrévost \& Zadra, 2007; Blagrove \& Akehurst, 2000; Levin et al., 2003; Zadra \& Domhoff, 2017). As demonstrated by Beaulieu-Prévost and Zadra (2015) remembering dream-experiences from the past is very fragile - false memories can easily be generated. Sometimes it is even hard to determine the origin of a memory: confusion regarding whether it was a dream or something that has really happened is a common feeling.

Moreover, these kind of scales do not make an effort to impose any systematic control on the variables affecting retrieval. Thus the time, the environment and the process of waking up, morning habits, and the attitude towards and interest in dreams, and therefore the motivation for retrieving them, which all show great variance between individuals, can significantly modulate retrospectively measured DRF. Even demand characteristics (Blagrove \& Akehurst, 2000), personality traits (Beaulieu-Prévost \& Zadra, 2005; Beaulieu-Prévost \& Zadra, 2007; Blagrove, 2007; Levin et al., 2003) and the self-concept of the individual (Bernstein \& Roberts, 1995) have serious impact on how DRF is judged on scale measures. These effects, by interacting mostly with the post-awakening step of dream reporting, can screen off the characteristics of the production and encoding of dreams, therefore dream recall scales are inappropriate choices for investigations that aim to get a better grip on these mechanisms.

\section{Conclusion}

The aim of this paper was to provide a crucial clarification for dream science to resolve an existing confusion regarding what different measures of dream recall can carry information about. The paper brought to centre stage the fact, rarely acknowledged in 
the literature, that dream recall depends on three important steps: the generation, the encoding and the retrieval of dreams. Emphasising this helps reorganise and reanalyse the relevant literature, which is necessary for fully appreciating the role of those theoretical assumptions that highly influence the answers to the question whether and to what extent the variability in dream recall reflects differences in the generation, the encoding or the retrieval of dreams. Most importantly, the paper draws attention to the fact that the different methods of measuring dream recall interact with the three steps differently.

Scale-based DRF is highly determined by factors affecting dream retrieval. Therefore, investigations using retrospective methods provide information not about the frequency of dreams per se, but rather about the factors that modulate the retrieval of dreams (and also the answers given on retrospective scales in general): contextual and motivational factors, the subjects' personality traits, self-concept and their tendency to pay attention to their dreams.

However, understanding the retrieval step of dream recall is not the issue that dream researchers are most interested in. The factors determining retrieval are quite clear. There is no doubt that memory fades over time (Roediger III, Weinstein, \& Agarwal, 2010). Similarly well known is that the allocation of attention during the encoding or the retrieval of an experience can highly influence future remembering (Dudukovic, DuBrow, \& Wagner, 2009; Mulligan, 2004). Most importantly, since the retrieval of a dream happens in the wakeful state, there is no reason to treat it distinctly from any other form of retrieval examined by studies focusing on memory.

What is more in the focus of current dream research, is trying to shed new light on the mechanisms of dream production and encoding. Since there is no direct tool available to measure the exact number of conscious experiences occurring during sleep, or the proportion of them that could successfully been encoded, we must rely on indicators like DRF. To get the most precise estimation possible, it is important to control for the variables that can negatively influence retrieval, and thus to keep the efficiency of retrieval at or close to its maximum. By maximising retrieval, false 
negative responses (there was a dream, but it couldn't be retrieved) decrease drastically, and thus cannot distort the data.

Therefore, to understand the state factors determining the intensity or quantity of dream production or the mechanisms of dream encoding, the best method is to collect dream reports right after awakenings in the laboratory. To reveal the trait variables determining the production or encoding of dreams, it is more suitable to use two-weeklong checklist-type dream logs capturing a person's dream recall capacity, since these provide better control over variables affecting retrieval than scale measures.

To further differentiate between the mechanisms of generation and encoding is less straightforward, as they are highly intertwined. In order to differentiate between them, the distinction between contentful versus contentless dream reports (i.e. white dreams) might be helpful. However, it is still debated whether white dreams only differ from contentful dreams regarding memory processes and are identical to them regarding dream production itself (Siclari et al., 2017), or whether there is a significant difference between them already in dream production (Fazekas et al., 2019). The question whether dream encoding is independent from or determined by the characteristics of dream generation is highly relevant for this debate. Answering this, and the further question of what features of dream generation might influence dream encoding are currently the biggest challenges for future research.

\section{References}

Addante, R. J., Watrous, A. J., Yonelinas, A. P., Ekstrom, A. D., \& Ranganath, C. (2011). Prestimulus theta activity predicts correct source memory retrieval. Proceedings of the National Academy of Sciences of the United States of America, 108, 10702-10707.

Åkerstedt, T., Billiard, M., Bonnet, M., Ficca, G., Garma, L., Mariotti, M., Saklzarulo, P., \& Schulz, H. (2002). Awakening from sleep. Sleep Medicine Reviews, 6(4), 267-286.

Ambrosius, U., Lietzenmaier, S., Wehrle, R., Wichniak, A., Kalus, S., Winkelmann, J., Bettecken, T., Holsboer, F., Yassouridis, A., \& Friess, E. (2008). Heritability of sleep electroencephalogram. Biological Psychiatry, 64, 344-348.

Anderson, M. C., \& Green, C. (2001). Supressing unwanted memories by executive control. Nature, 410, 366-369.

Anderson, M. C., \& Spellman, B. A. (1995). On the status of inhibitory mechanisms in cognition: Memory retrieval as a model of case. Psychological Reviews, 102, 68-100.

Antrobus, J. (1991). Dreaming: Cognitive processes during cortical activation and high afferent thresholds. Psychological Review, 98(1), 96-121.

Antrobus, J. (2000). How does the dreaming brain explain the dreaming mind? Behavioral and Brain Sciences, 23(6), 904-907. 
Antrobus, J. S., Dement, W. C., \& Fisher, C. (1964). Patterns of dreaming and dream recall: an EEG study. Journal of Abnormal and Social Psychology(69), 341-344.

Arkin, A. (1981). Sleep talking:Psychology and osychophysiology. Mahwah: NJ:Erlbaum.

Arkin, A., Battin, D., Gerber, I., \& Wiener, A. (1976). The effects of psychotherapy on the frequency of dreaming and reference to the decrease following bereavement in the aged. Sleep Research, 5, 134.

Armitage. (1992). Gender differences and the effect of stress on dream recall: a 30 day diary report. Dreaming, 2, 137-141.

Aspy, D. J. (2016). Is dream recall underestimated by retrospective measures and enhanced by keeping a logbook? An empirical investigation. Consciousness and Cognition, 42, 181-203.

Aspy, D. J., Delfabbro, P., \& Proeve, M. (2015). Is dream recall underestimated by retrospective measures and enhanced by keeping a logbook? A review. Consciousness and Cognition, 33, 364-374.

Baekeland, F. (1971). The effects of presleep procedures and cognitive style on dream content. Perceptual and Motor Skills, 32, 63-69.

Beaulieu-Prévost, D., \& Zadra, A. (2005). Dream recall frequency and attitude towards dreams: a reinterpretation of the relation. Personality and Individual Differences, 38(4), 919-927.

Beaulieu-Prévost, D., \& Zadra, A. (2007). Absorption, psychological boundaries and attitude towards dreams as correlates of dream recall: two decades of research seen through a meta-analysis. Journal of Sleep Research, 16(1), 51-59.

Beaulieu-Prévost, D., \& Zadra, A. (2015). When people remember dreams they never experienced: A study of the malleability of dream recall over time. Dreaming, 25(1), 18-31.

Bei, B., Wiley, J. F., Trinder, J., \& Manber, R. (2016). Beyond the mean: a systematic review on the correlates of daily intraindividual variability of sleep/wake patterns. Sleep Medicine Reviews, 28, 108-124.

Bernstein, D. M., \& Belicki, K. (1996). On the Psychometric Properties of Retrospective Dream Content Questionnaires. Imagination, Cognition and Personality, 15(4), 351-364.

Bernstein, D. M., \& Roberts, B. (1995). Assessing dreams through self-report questionnaires:relations with past reseach and personality. Dreaming, 5, 13-27.

Blagrove, M. (2007). Dreaming and personality. In D. Barrett \& P. McNamara (Eds.), The new science of dreaming (Vol. 2, pp. 115-158). London: Praeger Persppectives.

Blagrove, M., \& Akehurst, L. (2000). Personality and Dream Recall Frequency: Further Negative Findings. Dreaming, 10(3), 139-148.

Blagrove, M., \& Fisher, S. (2009). Trait-state interactions in the etiology of nightmares. Dreaming, 19(2), 65-74.

Blagrove, M., \& Pace-Schott, E. F. (2010). Trait and neurobiological correlates of individual differences in dream recall and dream content. International review of neurobiology, 92, 155-180.

Bódizs, R., Simor, P., Csóka, S., Bérdi, M., \& Kopp, M. S. (2008). Dreaming and health promotion: a theoretical proposal and some epidemiological establishments. JEuropean Journal of Mental Health, 3, 35-62.

Bone, R. N., Nelson, A. E., \& McAllister, D. S. (1970). Dream recall and repression-sensitization. Psychological Reports, 30, 58.

Brand, S., Beck, J., Kalak, N., Gerber, M., Kirov, R., Pühse, U., Hatzinger, M., \& Holsboer-Trachsler, E. (2011). Dream recall and its relationship to sleep, perceived stress, and creativity among adolescents. The Journal of adolescent health : official publication of the Society for Adolescent Medicine, 49(5), 525-531.

Braun, A. R., Balkin, T. J., Wesenten, N. J., Carson, R. E., Varga, M., Baldwin, P., Selbie, S., Belenky, G., \& Herscovitch, P. (1997). Regional cerebral blood flow throughout the sleep-wake cycle. An H2(15)O PET study. Brain, 120(7), 1173-1197.

Buchanan, T. W. (2007). Retrieval of emotional memories. Psychonomic Bulletin \&amp; Review, 133, 761-779.

Butler, S. F., \& Watson, R. (1985). Individual Differences in Memory for Dreams: The Role of Cognitive Skills. Perceptual and Motor Skills, 61(3), 823-828. 
Cartwright, R. (1996). Dreams and adaptation to divorce. In D. Barrett (Ed.), Trauma and dreams (pp. 179-185). Cambridge: Harvard University Press.

Cartwright, R. (2005). Dreaming as a Mood Regulation System. In M. H. Kryger, T. Roth \& W. C. Dement (Eds.), (pp. 565-572). Philadelphia.

Cicogna, P., Cavallero, C., \& Bosinelli, M. (1991). Cognitive aspects of mental activity during sleep. The American Journal of Psychology, 104(3), 413-425.

Cicogna, P., Natale, V., Occhionero, M., \& Bosinelli, M. (2000). Slow wave and REM sleep mentation. Sleep Research Online, 3, 67-72.

Cipolli, C., Bolzani, R., Cornoldi, C., De Beni, R., \& Fagioli, I. (1993). Bizarreness effect in dream recall. Sleep, 16(2), 163-170.

Cipolli, C., Fagioli, I., Baroncini, P., Fumai, A., B, M., \& Sancini, M. (1992). Recall of mental sleep experience with or without prior verbalization. American Journal of Psychology, 105, 385-407.

Cipolli, C., Ferrara, M., De Gennaro, L., \& Plazzi, G. (2017). Beyond the neuropsychology of dreaming: Insights into the neural basis of dreaming with new techniques of sleep recording and analysis. Sleep Medicine Reviews, 35, 8-20.

Cipolli, C., Guazzelli, M., Bellucci, C., Mazzetti, M., Palagini, L., Rosenlicht, N., \& Feinberg, I. (2015). Time-of-night variations in the story-like organization of dream experience developed during rapid eye movement sleep. Journal of Sleep Research, 24, 234-240.

Cohen, D. B. (1969). Frequency of dream recall estimated by three methods and related to defense preference and anxiety. Journal of consulting and clinical psychology, 33(6), 661-667.

Cohen, D. B. (1971). Dream recall and short-term memory. Perceptual and Motor Skills, 33(3), 867-871.

Cohen, D. B. (1974a). Presleep mood and dream recall. Journal of abnormal psychology, 83(1), 45-51.

Cohen, D. B. (1974b). Toward a theory of dream recall. Psychological bulletin, 81(2), 138-154.

Cohen, D. B. (1979). Sleep and dreaming: Origins, nature and functions. Oxford: Pergamon Press.

Cohen, D. B., \& MacNeilage, P. F. (1974). A test of the salience hypothesis of dream recall. Journal of consulting and clinical psychology, 42, 699-703.

Cohen, D. B., \& Wolfe, G. (1973). Dream recall and repression: evidence for an anternative hypothesis. Journal of consulting and clinical psychology, 41(3), 349-355.

Cohen, M. X. (2011). Hippocampal-prefrontal connectivity predicts midfrontal oscillations and long-term memory performance. Current Biology, 21, 1900-1905.

Conduit, R., Crewther, S. G., \& Coleman, G. (2000). Shedding old assumptions and consolidating what we know: Toward an attention-based model of dreaming. Behavioral and Brain Sciences, 23(6), 924-928.

Conduit, R., Crewther, S. G., \& Coleman, G. (2004). Spontaneous eyelid movements (ELMS) during sleep are related to dream recall on awakening. Journal of Sleep Research, 13, 137-144.

Cory, T. L., Ormiston, D. W., Simmel, E., \& Dainoff, M. (1975). Predicting the frequency of drem recall. Journal of abnormal psychology, 84, 261-266.

Crespin, L. (2015). “Are Dreams Experiences?”: Insights From Dreaming Considered as a Conscious Experience Under Constraint of Delayed Report. Dreaming, 25(2), 118-140.

D'Angiulli, A., Runge, M., Faulkner, A., Zakizadeh, J., Chan, A., \& Morcos, S. (2013). Vividness of Visual Imagery and Incidental Recall of Verbal Cues, When Phenomenological Availability Reflects Long-Term Memory Accessibility. Frontiers in Psychology, 4(1), 1-18.

Dang-Vu, T. T., Schabus, M., Desseilles, M., Schwartz, S., \& Maquet, P. (2007). Neuroimaging of REM Sleep and Dreaming. In D. Barrett \& P. McNamara (Eds.), The New Science of Dreaming (Vol. 1). Westport: Praeger Publishers.

De Gennaro, L., \& Ferrara, M. (2017). Brain Correlates of Successful Dream Recall. In M. H. Kryger, T. Roth \& W. C. Dement (Eds.), Principles and Practices of Sleep Medicine (Sixth ed., pp. 523-528). Philadelphia, PA: Elsevier.

De Gennaro, L., Marzano, C., Fratello, F., Moroni, F., Pellicciari, M. C., Ferlazzo, F., Costa, S., Couyoumdijian, A., Curcio, G., Sforza, E., Malafosse, A., Finelli, L. A., Pasqualetti, P., Ferrara, 
M., Bertini, M., \& Rossini, P. M. (2008). The electroencephalographic fingerprint of sleep is genetically determined: a twin study. Annals of Neurology, 64(4), 455-460.

Dement, W., \& Kleitman, N. (1957). The relation of eye movements during sleep to dream activity: an objective method for the study of dreaming. Journal of Experimental Psychology, 53, 339-346.

Dement, W., \& Wolpert, E. (1958). The relation of eye movements, body motility, and external stimuli to dream content. Journal of Experimental Psychology, 55, 543-553.

Domhoff, G. W. (1969). Home dreams versus laboratory dreams - Home dreams are better. In M. Kramer, R. M. Whitman, B. J. Baldridge \& P. H. Ornstein (Eds.), Dream psychology amd the new biology of dreaming (pp. 199-217): Springfield: Charles C. Thomas.

Domhoff, G. W. (2018). The Emergence of Dreaming: Mind-Wandering, Embodied Simulation, and the Default Network. New York: Oxford University Press.

Domhoff, G. W., \& Fox, K. C. R. (2015). Dreaming and the default network: A review, synthesis, and counterintuitive research proposal. Consciousness and Cognition, 33, 342-353.

Dudukovic, N. M., DuBrow, S., \& Wagner, A. D. (2009). Attention during memory retrieval enhances future remembering. Memory and Cognition, 37(7), 953-961.

Eichenlaub, J.-B., Bertrand, O., Morlet, D., \& Ruby, P. (2014a). Brain reactivity differentiates subjects with high and low dream recall frequencies during both sleep and wakefulness. Cerebral Cortex, 24(5), 1206-1215.

Eichenlaub, J.-B., Nicolas, A., Daltrozzo, J., Redouté, J., Costes, N., \& Ruby, P. (2014b). Resting brain activity varies with dream recall frequency between subjects. Neuropsychopharmacology, 39(7), 1594-1602.

Esposito, M. J., Nielsen, T. A., \& Paquette, T. (2004). Reduced alpha power associated with the recall of mentation from Stage 2 and Stage REM sleep. Psychophysiology, 41, 288-297.

Fazekas, P., \& Nemeth, G. (2018). Dream experiences and the neural correlates of perceptual consciousness and cognitive access. Philosophical Transactions of the Royal Society B: Biological Sciences, 373, 20170356.

Fazekas, P., Nemeth, G., \& Overgaard, M. (2019). White dreams are made of colours: What studying contentless dreams can teach about the neural basis of dreaming and conscious experiences. Sleep Medicine Reviews, 43, 84-91.

Fazekas, P., \& Overgaard, M. (2016). Multidimensional Models of Degrees and Levels of Consciousness. Trends in Cognitive Sciences, 20(10), 715-716.

Fazekas, P., \& Overgaard, M. (2018). A Multi-Factor Account of Degrees of Awareness. Cognitive Science, 42(6), 1833-1859.

Feinberg, I. (2000). REM sleep: Desperately seeking isomorphism. Behavioral and Brain Sciences, 23(6), 931-934.

Fell, J., Fernández, G., Klaver, P., Axmacher, N., Mormann, F., Haupt, S., \& Elger, C. E. (2006). Rhinalhippocampal coupling during declarative memory formation: dependence on item characteristics. Neuroscience letters, 407(1), 37-41.

Foulkes, D. (1985). Dreaming: a cognitive-psychological analysis. Hillsdale, NJ: Lawrence Erlbaum Associates.

Foulkes, D. (1999). Children's dreaming and the development of consciousnes. Cambridge, MA: Harvard University Press.

Foulkes, D., Pivik, T., Steadman, H. S., Spear, P. S., \& Symonds, J. D. (1967). Dreams of the mail child: an EEG study. Journal of abnormal psychology, 72, 457-467.

Foulkes, D., \& Rechtschaffen, A. (1964). Presleep determinants of dream content: effects of two films. Perceptual and Motor Skills, 19, 983-1005.

Fox, K. C. R., Spreng, R. N., Ellamil, M., Andrews-Hanna, J. R., \& Christoff, K. (2015). The wandering brain: meta-analysis of functional neuroimaging studies of mind-wandering and related spontaneous thought processes. NeuroImage, 111, 611-621.

Freud, S. (1964/1900). The interpretation of dreams. London: Hogarth. 
Giesbrecht, T., \& Merckelbach, H. (2006). Dreaming to reduce fantasy? - Fantasy proneness, dissociation, and subjective sleep experiences. Personality and Individual Differences, 41, 697-706.

Goodenough, D. R. (1991). Dream recall: history and current status of the field. In S. J. Ellman \& J. Antrobus (Eds.), The mind in sleep: psychology and psychophysiology (2nd ed.) (Vol. New York, pp. 143-171): John Wiley.

Goodenough, D. R., Shapiro, A., Holden, M., \& Steinschriber, L. (1959). A comparison of "dreamers" and "nondreamers": Eye movements, electroencephalograms, and the recall of dreams. Journal of Abnormal and Social Psychology, 59(3), 295-302.

Goodenough, D. R., Witkin, H. A., Lewis, H. B., Koulack, D., \& Cohen, H. (1974). Repression interference and filed dependence as factors in dream forgetting. Jornal of Abnormal Psychology, $83,32-44$.

Guderian, S., Schott, B. H., Richardson-Klavehn, A., \& Düzel, E. (2009). Medial temporal theta state before an event predicts episodic encoding success in humans. Proceedings of the National Academy of Sciences of the United States of America, 106(13), 5365-5370.

Halliday, G. (1992). Effect of encouragement on dream recall. Dreaming, 2, 39-44.

Hartmann, E. (2001). Dreams and Nightmares. New York: Peseus Publishing.

Hartmann, E. (2008). The central image makes "big" dreams big: The central image as the emotional heart of the dream. Dreaming, 18(1), 44-57.

Hartmann, E., \& Brezler, T. (2008). A systematic change in dreams after 9/11/01. Sleep, 31(2), 213-218.

Hartmann, E., Elkin, R., \& Garg, M. (1991). Personality and dreaming: the dreams of people with very thick and very thin boundaries. Dreaming, 1, 311-324.

Hartmann, E., Zborowski, M., Rosen, R., \& Grace, N. (2001). Contextualizing images in dreams: More intense after abuse and trauma. Dreaming, 11(3), 115-126.

Herlin, B., Leu-Semenescu, S., Chaumereuil, C., \& Arnulf, I. (2015). Evidence that non-dreamers do dream: a REM sleep behaviour disorder model. Journal of Sleep Research, 24(6), 602-609.

Hill, A. B. (1974). Personality correlates of dream recall. Journal of consulting and clinical psychology, 42, 766-773.

Hill, C. E., Diemer, R. A., \& Heaton, K. J. (1997). Dream interpretation sesssions: who volunteers, who benefits, and what volunteer cliens view as most and least helpful. Journal of Counseling Psychology, 44, 53-62.

Hiscock, M., \& Cohen, D. B. (1973). Visual imagery and dream recall. Journal of Research in Personality, 7, 179-188.

Hobson, A. (2001). The new neuropsychology of sleep: Implications for psychoanalysis. In K. Bulkeley (Ed.), Dreams: a reader on the religious, cultural, and psychological dimensions of dreamig ( $\mathrm{pp}$. 321-333). New York: Palgrave.

Hobson, A. (2014). The William James Lactures on Dream Consciousness. In N. Tranquillo (Ed.), Dream Consciousness (pp. 3-79). New York, NY: Springer.

Hobson, A., \& McCarley, R. W. (1977). The brain as a dream state generator: an activation-synthesis hypothesis of the dream process. American Journal of Psychiatry, 134, 1335-1348.

Hobson, A., Pace-Schott, E. F., \& Stickgold, R. (2000a). Dream science 2000: A response to commentaries onDreaming and the brain. Behavioral and Brain Sciences, 23(6), 1019-1035.

Hobson, A., Pace-Schott, E. F., \& Stickgold, R. (2000b). Dreaming and the brain: toward a cognitive neuroscience of conscious states. Behavioral and Brain Sciences, 23(6), 793-842.

Hobson, A., Pace-Schott, E. F., Stickgold, R., \& Kahn, D. (1998). To dream or not to dream? Relevant data from neuroimaging and electrophysiological studies. Current Opinion in Neurobiology, 8 , 239-244.

Kanzer, M. (1959). The recollection of the forgotten dream. Journal of Hillside Hospital, 8, 74-85.

Keklund, G., \& Åkerstedt, T. (1997). Objective components of individual differences in subjective sleep quality. Journal of Sleep Research, 6, 217-220.

Kensinger, E. A. (2009). Remembering the Details: Effects of Emotion. Emotion Review, 1(2), 99-113. 
Klimesch, W., Doppelmayr, M., Russeger, H., \& Pachinger, T. (1996). Theta band power in the human scalp EEG and the encoding of new information. NeuroImage, 7, 1235-1240.

Klimesch, W., Doppelmayr, M., Schimke, H., \& Rippel, B. (1997). Theta synchronization and alpha desynchronization in a memory task. Psychophysiology, 34, 169-176.

Klimesch, W., Doppelmayr, M., Stadler, W., Pöllhuber, D., Sauseng, P., \& Röhm, D. (2001). Episodic retrieval is reflected by a process specific increase in human electroencephalographic theta activity. Neuroscience letters, 302(1), 49-52.

Klimesch, W., Hanslmayr, S., Sauseng, P., Gruber, W., Brozinsky, C., Kroll, N. E., Yonelinas, A. P., \& Doppelmayr, M. (2006). Oscillatory EEG correlates of episodic trace decay. Cerebral Cortex, 16(2), 280-290.

Knutson, K. L., Rathouz, P. J., L, Y. L., Kiang, L., \& Lauderdale, D. S. (2007). Intra-Individual Daily and Yearly Variability in Actigraphically Recorded Sleep Measures: the CARDIA Study. Sleep, 30, 793-796.

Koukkou, M., \& Lehmann, D. (1983). Dreaming: The functional state-shift hypothesis. A neuropsychophysiological model. The British Journal of Psychiatry, 142, 221-231.

Koulack, D. (1991). To catch a dream: explorations of dreaming. New York: State University of New York Press.

Koulack, D., \& Goodenough, D. R. (1976). Dream recall and dream recall failure: An arousal-retrieval model. Psychological bulletin, 83(5), 975-984.

Kramer, M. (2007). The dream experience. A systematic exploration. New York: Routledge.

Kunzendorf, R. G., Hartmann, E., Cohen, R., \& Cutler, J. (1997). Bizarreness of the dreams and daydreams reported by individuals with thin and thick boundaries. Dreaming, 7(4), 265-271.

LaBerge, S. (1985). Lucid dreaming. Los Angeles: Jeremy Tacher.

Leclair-Visonneau, L., Oudiette, D., Gaymard, B., Leu-Semenescu, S., \& Arnulf, I. (2010). Do the eyes scan dream images during rapid eye movement sleep? Evidence from rapid eye movement sleep behaviour disorder model. Brain: A Journal of Neurology, 133, 1737-1746.

Levin, R., Fireman, G., \& Rackley, C. (2003). Personality and dream recall frequency: Still further negative findings. Dreaming, 13(3), 155-162.

Levin, R., \& Young, H. (2001-02). The relation of waking fantasy to dreaming. Imagination, Cognition and Personality, 21, 201-219.

Lewis, H. B., Goodenough, D. R., Shapiro, A., \& Sleser, I. (1966). Individual differences in dream recall. Journal of abnormal psychology, 71(1), 52-59.

Maquet, P., Péters, J.-M., Aerts, J., Delfiore, G., Degueldre, C., Luxen, A., \& Franck, G. (1996). Functional neuroanatomy of human rapid-eye-movement sleep and dreaming. Nature, 383, 163.

Marzano, C., Ferrara, M., Mauro, F., Moroni, F., Gorgoni, M., Tempesta, D., Cipolli, C., \& De Gennaro, L. (2011). Recalling and Forgetting Dreams: Theta and Alpha Oscillations during Sleep Predict Subsequent Dream Recall. The Journal of Neuroscience, 31(18), 6674.

Mason, M. F., Norton, M. I., Van Horn, J. D., Wegner, D. M., Grafton, S. T., \& Macrae, C. N. (2007). Wandering Minds: The Default Network and Stimulus-Independent Thought. Science, 315, 393-395.

Mezick, E. J., Matthews, K. A., Hall, M., Kamarck, T. W., Buysse, D. J., Owens, J. F., \& Reis, S. E. (2009). Intra-individual variability in sleep duration and fragmentation: Associations with stress. Psychoneuroendocrinology, 34(9), 1346-1354.

Mölle, M., Marshall, L., Fehm, H. L., \& Born, J. (2002). EEG theta synchronization conjoined with alpha desynchronization indicate intentional encoding. European Journal of Neuroscience, 15, 923-928.

Mulligan, N. (2004). Generation and memory for contextual detail. Journal of Experimental Psychology: Learning, Memory, \& Cognition, 30, 838-855.

Muzur, A., Pace-Schott, E. F., \& Hobson, J. A. (2002). The prefrontal cortex in sleep. Trends in Cognitive Sciences, 6(11), 475-481.

Najam, N., Mansoor, A., Kanwal, R. H., \& Naz, S. (2006). Dream content: Reflections of the emotional and psychological states of earthquake survivors. Dreaming, 16(4), 237-245. 
Nemeth, G., \& Fazekas, P. (2018). Beyond the REM-NREM dichotomy: A multi-dimensional approach to understanding dreaming. Journal of Consciousness Studies, 25(11-12), 13-33.

Nielsen, T. A. (2000). A review of mentation in REM and NREM sleep: "covert" REM sleep as a possible reconciliation of two opposing models. Behavioral and Brain Sciences, 23(6), 851-866.

Nielsen, T. A. (2012). Variations in dream recall frequency and dream theme diversity by age and sex. Frontiers in neurology, 3, 106.

Nielsen, T. A., Carr, M., Blanchette-Carrière, C., Marquis, L.-P., Dumel, G., Solomonova, E., Julien, S.H., Picard-Deland, C., \& Paquette, T. (2017). NREM sleep spindles are associated with dream recall. Sleep Spindles \& Cortical Up States, 1, 27-41.

Overton, D. A. D. d. t. w. p. 1. d. S., 205, 720-1. (1979). Drug discrimination training with progressively lowered doses. Science, 205, 720-721.

Pace-Schott, E. F. (2007). The frontal lobes and dreaming. In D. Barrett \& P. McNamara (Eds.), The New Science of Dreaming (Vol. 1, pp. 115-155). Westport: Praeger Publishers.

Pagel, J. F. (2003). Non-dreamers. Sleep medicine, 4(3), 235-241.

Pagel, J. F., \& Shocknesse, S. (2007). Dreaming and insomnia: Polysomnographic correlates of reported dream recall frequency. Dreaming, 17(3), 140-151.

Parke, A. R., \& Horton, C. L. (2009). A re-examination of the interference hypothesis on dream recall and dream salience. International Journal of Dream Research, 2, 60-69.

Pesant, N., \& Zadra, A. (2006). Dream content and psychological well-being: a longitudinal study of the continuity hypothesis. Journal of clinical psychology, 62(1), 111-121.

Punamäki, R. L. (2007). Trauma and dreaming: Trauma impact on dream recall, content, and patterns, and the mental health function of dreams.

Rechtschaffen, A., Hauri, P., \& Zeitlin, M. (1966). Auditory awakening thresholds in Rem and Nrem sleep stages. Perceptual and Motor Skills, 22(3).

Redfering, D. L., \& Keller, J. N. (1974). Influence of diffrential instructions on the frequency of dream recall. Journal of clinical psychology, 30(3), 268-271.

Robbins, P. R., \& Tanck, R. H. (1978). Early memories and dream recall. Journal of clinical psychology, 34(3), 729-731.

Robert, G., \& Zadra, A. (2008). Measuring nightmare and bad dream frequency: impact of retrospective and prospective instruments. Journal of Sleep Research, 17(2), 132-139.

Robert, G., \& Zadra, A. (2014). Thematic and content analysis of idiopathic nightmares and bad dreams. Sleep.

Roediger III, H. L., Weinstein, Y., \& Agarwal, P. K. (2010). Forgetting: Preliminary considerations. In S. Della Sala (Ed.), Forgetting: current issues in memory (pp. 1-23). New York: Psychology Press.

Rofe, Y., \& Lewin, I. (1979). Who adjust better: repressors or sensitisers? Journal of clinical psychology, $35,875-879$.

Rosen, M. (2013). What I make up when I wake up: anti-experience views and narrative fabrication of dreams. Frontiers in Psychology, 4(514).

Rosenlicht, N., Maloney, T., \& Feinberg, I. (1994). Dream report length is more dependent on arousal level than prior REM duration. Brain research bulletin, 34(2), 99-101.

Rosipal, R., Lewandowski, A., \& Dorffner, G. (2013). In search of objective components for sleep quality indexing in normal sleep. Biological psychology, 94, 210-220.

Scarpelli, S., D'Atri, A., Gorgoni, M., Ferrara, M., \& De Gennaro, L. (2015). EEG oscillations during sleep and dream recall: state- or trait-like individual differences? Frontiers in Psychology, 6, 605.

Scarpelli, S., D’Atri, A., Mangiaruga, A., Marzano, C., Gorgoni, M., Schiappa, C., Ferrara, M., \& De Gennaro, L. (2017). Predicting Dream Recall: EEG Activation During NREM Sleep or Shared Mechanisms with Wakefulness? Brain Topography, 30(5), 629-638.

Schonbar, R. A. (1965). Differential dream recall frequency as a componant of"life style". Journal of Consulting Psychology, 29, 468-474.

Schredl, M. (1995). Traumerinnerung: Persönlichkeitdimensions oder von situativan Faktoren beeinflusst? Psychologische Beiträge. Psychologische Beiträge, 37, 133-180. 
Schredl, M. (2002). Questionnaires and diaries as research instruments in dream research:

Methodological issues. Dreaming, 12(1), 17-26.

Schredl, M. (2004). Reliability and stability of a dream recall frequency scale. Perceptual and Motor Skills, 98(3), 1422.

Schredl, M. (2007). Dream Recall: Models and Empirical Data. In D. Barrett \& P. McNamara (Eds.), The New Science of Dreaming (Vol. Vol. 2, pp. 79-115). Westport: Praeger.

Schredl, M. (2008). Dream recall frequency in a representative German sample. Perceptual and Motor Skills, 106(3), 699-702.

Schredl, M. (2009). Recall Frequency of Positive and Negative Dreams in a Representative German Sample. Perceptual and Motor Skills, 108(3), 677-680.

Schredl, M. (2010). Explaining the gender difference in dream recall frequency. Dreaming, 20(2), 96-106.

Schredl, M. (2018). Researching Dreams: The Fundamentals. Mannheim: Palgrave Macmillan.

Schredl, M., Berres, S., Klingauf, A., \& Schellhaas, S. (2014). The Mannheim Dream questionnaire (MADRE): retest reliability, age and gender effects. International Journal of Dream Research, $7(2), 141-147$.

Schredl, M., Ciric, P., Götz, S., \& Wittmann, L. (2003a). Dream Recall Frequency, Attitude Towards Dreams and Openness to Experience. Dreaming, 13(3), 145-153.

Schredl, M., Frauscher, S., \& Shendi, A. (1995). Dream recall and visual memory. Perceptual and Motor Skills, 81(1), 256-258.

Schredl, M., \& Fulda, S. (2005a). Dream recall and sleep duration: state or trait factor. Perceptual and Motor Skills, 101(2), 613-616.

Schredl, M., \& Fulda, S. (2005b). Reliability and stability of dream recall frequency. Dreaming, 15, 240-244.

Schredl, M., Funkhouser, A. T., Cornu, C. M., Hirsbrunner, H. P., \& Bahro, M. (2001). Reliability in dream research: a methodological note. Consciousness and Cognition, 10(4), 496-502.

Schredl, M., \& Göritz, A. S. (2017). Dream recall frequency, attitude toward dreams, and the Big Five personality factors. Dreaming, 27(1), 49-58.

Schredl, M., Jochum, S., \& Souguenet, S. (1997). Dream recall, visual memory, and absorption in imaginings. Personality and Individual Differences, 22(2), 291-292.

Schredl, M., Kleinferchner, P., \& Gell, T. (1996). Dreaming and personality: Thick vs thin boundaries. Dreaming, 6, 219-223.

Schredl, M., \& Montasser, A. (1996/1997). Dream recall: State or trait variable? Part I: Model, theories, methodology and trait factors and Part II: State factors, investigations, and final conclusions. Imagination, Cognition and Personality, 16, 181-210, 231-261.

Schredl, M., \& Reinhard, I. (2008a). Dream recall, dream length, and sleep duration: state or trait factor. Perceptual and Motor Skills, 106(2), 633-636.

Schredl, M., \& Reinhard, I. (2008b). Gender differences in dream recall: a meta-analysis. Journal of Sleep Research, 17(2), 125-131.

Schredl, M., Schafer, G., Weber, B., \& Heuser, I. (1998). Dreaming and insomnia: Dream recall and dream content of patients with insomnia. Journal of Sleep Research, 7(3), 191-198.

Schredl, M., Wittmann, L., Ciric, P., \& Götz, S. (2003b). Factors of home dream recall: a structural equation model. Journal of Sleep Research, 12(2), 133-141.

Sehulster, J. R. (1981). Structure and pragmatics of a self-theory of memory. Memory \&amp; cognition, 9(3), 263-276.

Shapiro, A., Goodenough, D. R., Lewis, H. B., \& Sleser, I. (1965). Gradual arousal from sleep: a determinant of thinking reports. Psychosomatic Medicine, 27, 342-349.

Siclari, F., Baird, B., Perogamvros, L., Bernardi, G., LaRocque, J. J., Riedner, B., Boly, M., Postle, B. R., \& Tononi, G. (2017). The neural correlates of dreaming. Nature Neuroscience, 24(6), 171-878.

Siclari, F., LaRocque, J., Postle, B., \& Tononi, G. (2013). Assessing sleep consciousness within subjects using a serial awakening paradigm. Frontiers in Psychology, 4(542). 
Solms, M. (2000a). Dreaming and REM sleep are controlled by different brain mechanisms. Behavioral and Brain Sciences, 23(6), 843-850.

Solms, M. (2000b). Forebrain mechanisms of dreaming are activated from a variety of sources. Behavioral and Brain Sciences, 23(6), 1035-1040.

Solms, M., \& Turnbull, O. (2002). The brain and the inner world: Other Press.

Steyer, R., Mayer, A., Geiser, C., \& Cole, D. (2015). A theory of states and traits - revised. Annual Review of Clinical Psychology, 11, 71-98.

Stickgold, R., Pace-Schott, E. F., \& Hobson, A. (1994). A new paradigm for dream research: Mentation reports following spontaneous arousal from REM and NREM sleep recorded in a home setting. Consciousness and Cognition, 3, 16-29.

Takeuchi, T., Ogilvie, R. O., Murphy, T. I., \& Ferrelli, A. V. (2003). EEG activities during elicited sleep onset REM and NREM periods reflect different mechanisms of dream generation. Clinical Neurophysiology, 114, 210-220.

Tarokh, L., Carskadon, M., \& Achermann, P. (2011). Trait-like characteristics of the sleep EEG across adolescent development. Journal of Neuroscience, 31(17), 6371-6378.

Tart, C. T. (1962). Frequency of dream recall and some personality measures. Journal of Consulting Psychology, 26, 467-470.

Tassi, P., \& Muzet, A. (2000). Sleep inertia. Sleep Medicine Reviews, 4, 341-353.

Taub, J. M. (1970). Dream recall and content following extended sleep. Perceptual and Motor Skills, 30, 987-990.

Trinder, J., \& Kramer, M. (1971). Dream recall. American Journal of Psychiatry, 128, 296-301.

Trotti, L. M. (2017). Waking up is the hardest thing I do all day: sleep inertia and sleep drunkenness. Sleep Medicine Reviews, 35, 76-84.

Tversky, A., \& Kahneman, D. (1973). Availability: A heuristic for judging frequency and probability. Cognitive Psychology, 5, 207-232.

Vallat, R., Lajnef, T., Eichenlaub, J.-B., Berthomier, C., Jerbi, K., Morlet, D., \& Ruby, P. M. (2017). Increased Evoked Potentials to Arousing Auditory Stimuli during Sleep: Implication for the Understanding of Dream Recall. Frontiers in Human Neuroscience, 11, 132.

Valli, K., Frauscher, B., Gschliesser, V., Wolf, E., Falkenstetter, T., Schönwaldö, S. V., Ehrmann, L., Zangerl, A., Marti, I., Boesch, S. M., Revonsuo, A., Poewe, W., \& Högl, B. (2012). Can observers link dream content to behaviours in rapid eye movement sleep behaviour disorder? A crosssectional experimental pilot study. Journal of Sleep Research, 21(1), 21-19.

Valli, K., Revonsuo, A., Pälkäs, O., \& Punamäki, R.-L. (2006). The effect of trauma on dream content--A field study of Palestinian children. Dreaming, 16(2), 63-87.

Vedfelt, O. (1999). The dimensions of dreams: The neture, function and interpretation of dreams. New York: Fromm International Publishing Corporation.

Wamsley, E. J., \& Antrobus, J. (2007). Dream Production: A Neural Network Attractor, Dual Rhythm Regional Cortical Activation, Homeostatic Model. In A. Barrett \& P. McNamara (Eds.), The New Science of Dreaming (Vol. 1, pp. 155-183). Westport, CT: Praeger.

Watson, D. (2003). To dream, perchance to remember: individual differences in dream recall. Personality and Individual Differences, 34(7), 1271-1286.

Webb, W. B., \& Kersey, J. (1967). Recall of dreams and the probability of stage 1-REM sleep. Perceptual and Motor Skills, 24, 627-630.

Williamson, R. W., Heckel, R. V., \& Boblitt, E. (1970). Reported frequency of dream recall as related to repression-sensitization and intelligence. Journal of clinical psychology, 26, 300-301.

Windt, J. M. (2013). Reporting dream experience: Why (not) to be skeptical about dream reports. Frontiers in Human Neuroscience, 7(708).

Windt, J. M., Nielsen, T., \& Thompson, E. (2016). Does Consciousness Disappear in Dreamless Sleep? Trends in Cognitive Sciences, 20(12), 871-882.

Wood, J. M., \& Bootzin, R. R. (1990). The prevalence of nightmares and their independence from anxiety. Journal of abnormal psychology, 99(1), 64-68. 
Zadra, A., \& Domhoff, G. W. (2017). Dream Content: Quantitative Findings. In M. H. Kryger, T. Roth \& W. Dement (Eds.), Principles and Practice of Sleep Medicine (Sixth Edition ed., pp. 515-522). Saint-Louis, Missouri: Saunders-Elsevier.

Zadra, A., \& Donderi, D. C. (2000). Nightmares and bad dreams: their prevalence and relationship to well-being. Journal of abnormal psychology, 109(2), 273-281.

Zadra, A., \& Robert, G. (2012). Dream recall frequency: impact of prospective measures and motivational factors. Consciousness and Cognition, 21(4), 1695-1702.

Zou, Q., Zhou, S., Xu, J., Su, Z., Li, Y., Ma, Y., Sun, H., Wu, C. W., \& J-H, G. (2018). Dissociated resting-state functional networks between the dream recall frequency and REM sleep percentage. NeuroImage, 174, 248-256. 